\title{
HBV evolution and genetic variability: impact on prevention, treatment and
}

\section{development of antivirals}

Dieter Glebe ${ }^{1,5^{*}}$, Nora Goldmann ${ }^{1}$, Chris Lauber ${ }^{2,3,5}$, Stefan Seitz ${ }^{2,4,5^{*}}$

(1) Institute of Medical Virology, Justus Liebig University of Giessen, National Reference Centre for Hepatitis B Viruses and Hepatitis D Viruses, Schubertstr. 81, 35392, Giessen, Germany

(2) Division of Virus-Associated Carcinogenesis, German Cancer Research Center (DKFZ), 69120 Heidelberg, Germany

(3) Research Group Computational Virology, Institute for Experimental Virology, TWINCORE, Centre for Experimental and Clinical Infection Research, a joint venture between the Helmholtz Centre for Infection Research and the Hannover Medical School; Cluster of Excellence RESIST, Hannover Medical School, 30625 Hannover, Germany

(4) Department of Infectious Diseases, Molecular Virology, University of Heidelberg, 69120 Heidelberg, Germany

(5) German Center for Infection research (DZIF), Partner Sites Giessen, Hannover \& Heidelberg

*Corresponding authors:

Dieter Glebe, E-Mail: dieter.glebe@viro.med.uni-giessen.de

Stefan Seitz, E-Mail: s.seitz@dkfz-heidelberg.de 


\section{Abstract}

Hepatitis B virus (HBV) poses a major global health burden with 260 million people being chronically infected and 890,000 dying annually from complications in the course of the infection. HBV is a small enveloped virus with a reverse-transcribed DNA genome that infects hepatocytes and can cause acute and chronic infections of the liver. HBV is endemic in humans and apes representing the prototype member of the viral family Hepadnaviridae and can be divided into 10 genotypes. Hepadnaviruses have been found in all vertebrate classes and constitute an ancient viral family that descended from non-enveloped progenitors more than 360 million years ago. The de novo emergence of the envelope protein gene was accompanied with the liver-tropism and resulted in a tight virus-host association. The oldest HBV genomes so far have been isolated from human remains of the Bronze Age and the Neolithic ( 7,000 years before present). Despite the remarkable stability of the hepadnaviral genome over geological eras, $\mathrm{HBV}$ is able to rapidly evolve within an infected individual under pressure of the immune response or during antiviral treatment. Treatment with currently available antivirals blocking intracellular replication of HBV allows controlling of high viremia and improving liver health during long-term therapy of patients with chronic hepatitis B (CHB), but they are not sufficient to cure the disease. New therapy options that cover all HBV genotypes and emerging viral variants will have to be developed soon. In addition to the antiviral treatment of chronically infected patients, continued efforts to expand the global coverage of the currently available HBV vaccine will be one of the key factors for controlling the rising global spread of HBV. Certain improvements of the vaccine (e.g. inclusion of PreS domains) could counteract known problems such as low or no responsiveness of certain risk groups and waning anti-HBs titers leading to occult infections, especially with HBV genotypes E or F. But even with an optimal vaccine and a cure for hepatitis B, global eradication of HBV would be difficult to achieve because of an existing viral reservoir in primates and bats carrying closely related hepadnaviruses with zoonotic potential. 


\section{Introduction}

Despite the availability of a highly efficient recombinant vaccine for more than 30 years (Huzair and Sturdy, 2017), the number of individuals persistently infected with the human hepatitis B virus (HBV) is still increasing (Thomas, 2019). In 2015, about 260 million people worldwide were chronic HBV carriers living at high risk of developing liver cirrhosis and hepatocellular carcinoma (HCC). The infection with HBV resulted in approximately 890 thousand deaths in 2015, and the trend is on the rise (WHO, 2019). Currently, the annual death toll associated with hepatitis B is estimated to have exceeded that of HIV and malaria (Thomas, 2019). According to the WHO, only roughly $11 \%$ of the affected individuals have been diagnosed with hepatitis B (HB) and are thus aware of being infected; less than $2 \%$ of the chronically infected patients have access to state-of-the-art antiviral treatment (WHO, 2019). In light of this factual under-diagnosis and under-treatment, it is the inhabitants of low-income countries who suffer most from this plague (O'Hara et al., 2017).

The causative agent is a small enveloped DNA virus which appears in electron micrographs as a double-shelled spherical particle with a diameter of $42 \mathrm{~nm}$ (Dane et al., 1970; Dryden et al., 2006; Seitz et al., 2007) (Figure 1A). The inner shell of the infectious virion is an icosahedral capsid assembled from 240 Core (C) protein subunits (Böttcher et al., 1997; Conway et al., 1997; Wynne et al., 1999) (Figure 1B). The capsid contains the viral replication complex composed of a reversetranscribed, partially double-stranded circular DNA genome, covalently attached to a copy of the viral polymerase $\mathrm{P}$ (Seeger and Mason, 2000). This nucleocapsid is enclosed into an outer shell, a lipid bilayer derived from the host ER membrane into which the three envelope proteins L (large), M (middle) and S (small) are embedded - collectively referred to as hepatitis B surface antigen (HBsAg or shortly HBs) (Heermann et al., 1984; Seitz et al., 2016). In the bloodstream of infected persons, intact virions are outnumbered by a $10^{3}$ - to $10^{6}$-fold excess of subviral particles (SVP) consisting only of empty envelopes (Heermann et al., 1984). 
The circular genome of HBV encompasses just 3.2 kilobases $(\mathrm{kb})$ comprising four open reading frames (ORFs) (Gerlich et al., 2020; Seeger and Mason, 2000) (Figure 1C). The C ORF encodes the 183 amino acids (aa) of the capsid protein. Translation initiation at the next in-frame start codon upstream of the C start gives rise to the Precore (PreC/C) protein (Wang et al., 2020), which after proteolytic processing becomes secreted into the serum as e-antigen ( $\mathrm{HBeAg})$, a diagnostic marker of the viral replication activity (Kramvis et al., 2018). The viral polymerase is encoded by the P ORF and can be subdivided into three functional domains: The terminal protein (TP) domain serves as protein primer to initiate minus-strand DNA synthesis during reverse transcription of the pregenomic RNA (pgRNA); it is separated from the reverse transcriptase $(\mathrm{RT})$ and $\mathrm{RNase} H(\mathrm{RH})$ domains of $\mathrm{P}$ by a flexible spacer region (Bartenschlager and Schaller, 1988). The three envelope proteins are expressed from a single ORF (PreS1/PreS2/S) by utilization of alternative in-frame start codons (Heermann et al., 1984). The fourth ORF codes for the $\mathrm{X}$ protein $(\mathrm{HBx})$ required for establishment and maintenance of infection and involved in hepatocarcinogenesis (Minarovits and Niller, 2019; Slagle and Bouchard, 2018) (Figure 1C).

\section{HBV evolution}

\subsection{Hepadnaviridae - an ancient viral family}

The infectious nature of the certain forms of hepatitis was known at least since the end of the 19th century, but the viral origin of hepatitis B could only be determined in the $60 \mathrm{~s}$ and $70 \mathrm{~s}$ of the 20th century (Gerlich, 2013). HBV is the prototype member of the increasingly large viral family Hepadnaviridae. The first non-human hepatitis B viruses had been identified in woodchucks (WHV) (Summers et al., 1978), squirrels (Marion et al., 1980; Testut et al., 1996) and ducks (DHBV) (Mason et al., 1980). In particular WHV and DHBV served as indispensable surrogate systems to study the molecular biology of HBV in the past (Roggendorf et al., 2015; Schultz et al., 2004), before cell lines fully supportive for HBV infection became available (Watashi et al., 2014). In the subsequent years, 
several more hepadnaviruses were found in birds (genus Avihepadnavirus) by classical methods of molecular virology (Chang et al., 1999; Guo et al., 2005; Jo et al., 2017; Piasecki et al., 2012; Prassolov et al., 2003; Pult et al., 2001). In the same way, a mammalian hepadnavirus (WMHBV) was isolated from the woolly monkey, a New World primate (Lanford et al., 1998).

With the advent of next-generation sequencing techniques, the frequency of newly described hepadnaviral species accelerated dramatically. In the recent years, many novel species from diverse mammalian hosts (genus Orthohepadnavirus) have been detected in bats (Drexler et al., 2013; He et al., 2013a; He et al., 2013b; Hiller et al., 2019; Lei et al., 2019; Nie et al., 2018; Wang et al., 2017; Yang et al., 2018), in shrews (Nie et al., 2019; Rasche et al., 2019), in the domestic cat (Aghazadeh et al., 2018), in the capuchin monkey (de Carvalho Dominguez Souza et al., 2018), and in Maxwell's duiker (Gogarten et al., 2019), a small antelope from West Africa. Hepatitis B viruses meanwhile have been discovered in all other classes of bony vertebrates, too, i.e. in reptiles (Lauber et al., 2017), amphibians (Dill et al., 2016; Lauber et al., 2017) and ray-finned fishes (Dill et al., 2016; Hahn et al., 2015; Lauber et al., 2017) (Figure 1D).

Very intriguing and fundamental to our understanding of the evolutionary history of the whole virus family was the observation that certain hepadnaviral lineages integrated into the genomes of their hosts' germline and subsequently became fixed as endogenous viral elements (EVEs) (Feschotte and Gilbert, 2012; Patel et al., 2011). Such endogenization events occurred independently in birds (Gilbert and Feschotte, 2010; Lauber et al., 2017; Suh et al., 2013), crocodiles (Suh et al., 2014), snakes (Gilbert et al., 2014; Lauber et al., 2017; Suh et al., 2014), lizards (Lauber et al., 2017) and turtles (Suh et al., 2014) several tens to hundreds of million years ago (mya). The proneness of birds and reptiles to germline invasion of hepadnaviral sequences might result from the looser tissue tropism of these peculiar viruses able to infect a wide range of glandular organs.

A second step toward deeper insight into hepadnavirus evolution was the discovery of a related family of non-enveloped fish viruses, termed nackednaviruses, which share similarities with regard to 
the genome organization, the mode of protein-primed reverse transcription and the ultrastructure of the viral capsids (Lauber et al., 2017) (Figure 1E).

\subsection{Reconstructing the origin and evolutionary history of hepadnaviruses}

Nackednaviruses represented the ideal outgroup to safely root the phylogenetic tree of hepatitis B viruses for the very first time, while the inclusion of an avian EVE of known age (eAHBV-FRY) enabled time-calibrating this phylogeny. These analyses suggest that both virus families separated from a common ancestor in the Silurian about 430 mya concomitant with the divergence of ray-finned fishes (Actinopterygii) and lobe-finned fishes (Sarcopterygii), the latter ones including all terrestrial vertebrates (Tetrapoda). The envelope protein gene in the hepadnaviral lineage emerged de novo in a rather short window of time between 380 and 360 mya, concomitant with the rise of the first tetrapods (Figure 2).

Since then, these viruses coevolved in intimate association with their respective host lineages. On the deep evolutionary scale, virus-host cospeciation appears to dominate, although some successful host jumps across vertebrate classes occurred. The gain of the envelope protein gene represents a fundamental transition in viral lifestyle. We assume that it was directly involved in the development of the hepatotropism, which in turn might have resulted in narrowing the host tropism limiting crossspecies transmission.

Subsequently, several independent "innovations" appeared in the distinct branches of the viral family. In the lineage leading to avi- and herpetohepadnaviruses, the C ORFs became elongated due to several insertions (Figure 2). The largest C protein to date is found in the skink hepatitis B virus (SkHBV) and comprises 335 aa (vs. 183 aa in human HBV). In a common ancestor of ortho- and metahepadnaviruses, the latter infecting fishes, the $a$-determinant emerged. This insertion into the $\mathrm{S}$ ORF constitutes the major immunogenic ectodomain on the viral particle surface, against which the 
anti-HBs response is directed (see also Figure 5). Finally, the X ORF originated in the ancestry unique to orthohepadnaviruses (Figure 2; see also Figure 1C and D).

The strong association of hepadnaviruses with their hosts over geologic eras suggests that the rate of viral macroevolution approximates that of their hosts. This synchronicity stays in sharp contrast to much faster rates of viral molecular evolution observed within infected individuals (Tedder et al., 2013). In line with the latter are findings from a study on intra- and inter-host evolution in a family of chronic HBV carriers across three generations covering a 100 -year period of virus diversification (Lin et al., 2015). The viral evolutionary rate within each family member during the years of chronic infection was found to be significantly faster than that between the carriers in the vertical (motherto-infant) transmission chains. Importantly, the authors observed an accumulation of nonsynonymous substitutions at immune epitopes of structural genes in the viral quasispecies within each individual. To explain the difference in substitution rates within and between hosts, the authors hence proposed the viral mutant spectrum to switch between colonization and adaptation. "Colonizers" are thought to represent optimally replicating viruses that are in advantage early after transmission into an immunologically naive host, particularly in newborns or immune-compromised persons. "Adaptors", on the other side, diversify under pressure of the host immune system during the late inflammatory phase of chronic infection at the cost of replicative fitness. The fast intra-host evolutionary rates are hence attributed to the divergence of the "adaptors," whereas the backselection toward "colonizers" succeeding each transmission event is thought to be responsible for the slow viral macroevolution.

\subsection{HBV host range and genotypes}

Natural hosts for HBV are humans and non-human apes (=hominoids; superfamily Hominoidea) (Grethe et al., 2000; Robertson and Margolis, 2002; Starkman et al., 2003). Isolates of human origin cluster into at least 9 genotypes (A-I, and the provisional $10^{\text {th }}$ genotype J), and sub-genotypes thereof 
(Kramvis, 2014; Schaefer, 2007; Tatematsu et al., 2009; Velkov et al., 2018). The viral strains found to circulate in non-human apes constitute two distinct branches interspersed into the phylogeny of human HBV genotypes (Figure 3). One branch comprises the isolates from African apes, i.e. chimpanzees and gorillas (Hu et al., 2001; MacDonald et al., 2000; Njouom et al., 2010; Takahashi et al., 2000); the other one contains those from Asian apes, i.e. gibbons and orangutans (Noppornpanth et al., 2003; Sa-nguanmoo et al., 2008; Sall et al., 2005; Verschoor et al., 2001; Warren et al., 1999). Neither the phylogenetic pattern, nor the geographic distribution of the genotypes is compatible with an exclusive mode of virus-host co-divergence and co-spreading (Littlejohn et al., 2016), but rather indicates that independent introductions into the respective host populations occurred repeatedly in the past. The picture gets even more complicated by frequent recombination events between genotypes (Araujo, 2015; Bollyky et al., 1996; Castelhano et al., 2017; Morozov et al., 2000; Shi et al., 2012; Simmonds and Midgley, 2005; Yang et al., 2007).

The advent of techniques to isolate and sequence ancient DNA opened the possibility not only to trace (pre)historic waves of human migration (Stoneking and Krause, 2011), but also to recover genome sequences of pathogens infesting these peoples (Spyrou et al., 2019). The first historic HBV genomes have been detected in a Korean mummy (Kahila Bar-Gal et al., 2012) and an Italian child mummy (Patterson et al., 2018), both from the $16^{\text {th }}$ Century. Recently, two studies isolated ancient HBV from human body remains of individuals who lived in Eurasia in the Medieval, the Bronze Age and the Neolithic up to 7.000 years before present (Krause-Kyora et al., 2018; Muhlemann et al., 2018). Surprisingly, several of these ancient HBV strains are phylogenetically most closely related to those viral isolates endemic in present-day African apes (Figure 3).

\subsection{Dating and tracing the origin and dispersal of HBV genotypes}

Former divergence time estimates for the extant HBV genotypes were based on molecular clock models in which substitution rates were derived by relating the genetic distances between viral 
sequences to the year of virus isolation. These approaches inferred time estimates for the most recent common ancestor (MRCA) ranging from several hundred to 7,000 years before present (Godoy et al., 2013; Mizokami and Orito, 1999; Orito et al., 1989; van Hemert et al., 2011). Inclusion of the Bronze Age strains retrieved a median age estimate for the MRCA of 12,000 years (Muhlemann et al., 2018), pointing out the ambiguity of these molecular clock approaches. Further evidence for a much slower evolutionary rate of virus evolution on deep time scales and thus a higher age of the MRCA came from the observation that the two Neolithic strains were more similar to each other than to any other HBV isolate, although the infected carriers had lived almost 2.000 years apart (7,000 vs. 5,000 years before present) (Krause-Kyora et al., 2018).

The alternative dating method using avihepadnaviral EVEs for phylogenetic tree calibration revealed a more than 1000-fold higher age estimate for the HBV MRCA (Lauber et al., 2017). According to this analysis, the HBV genotypes started to diversify about 30 mya (Figure 4) concomitant with the adaptive radiation and geographic dispersal of early hominoids across Africa and Eurasia (Begun, 2003; Bohme et al., 2019; Springer et al., 2012; Stevens et al., 2013).

Since there is no species barrier for HBV to be transmitted between humans and extant apes, we suggest that the same also applied to the plethora of extinct hominoids during their complex evolutionary history since the late Oligocene. Thus, HBV might have been freely floating within and between ancient ape species, whenever they came into local contact with each other in the past. This assumption is supported by the finding of recombination between chimpanzee and gorilla HBV strains circulating in the wild (Lyons et al., 2012; Yang et al., 2007). Moreover, an isolate from an East African wild-born chimp showed evidence for inter-host recombination with human HBV genotype C (Magiorkinis et al., 2005). Consequently, the diverse genotypes as we see them nowadays might have originated from ancient virus-host co-speciation events and successive (and still ongoing) host jumps accompanied by recombination events. 
Recent studies on prehistoric genetic admixture found that anatomically modern humans not only successfully interbred with Neanderthals (Green et al., 2010; Prufer et al., 2014) and Denisovans (Browning et al., 2018; Meyer et al., 2012) in Eurasia, but also with a yet unknown sort of archaic humans in West-Africa 40,000 years before present (Durvasula and Sankararaman, 2020; Hammer et al., 2011). The ancestors of Neanderthals and Denisovans in turn interbred with a "superarchaic" Eurasian population that separated from other human populations about 2 mya (Rogers et al., 2020). It is more than likely that on such occasions of productively exchanging genetic material between distantly related human populations, a less pleasant exchange of pathogens happened, too. Therefore, we propose that anatomically modern humans, during their expansion out of Africa across the whole Old World, picked up and became the melting pot for a diverse spectrum of preexisting HBV genotypes. Since then, some of these genotypes might have disappeared from mankind again, such as those Neolithic and Bronze Age strains clustering with the isolates from African apes (KrauseKyora et al., 2018; Muhlemann et al., 2018), while others were reshaped to a certain degree by recombination to form the variability and geographic distribution pattern we observe today (Muhlemann et al., 2018).

\subsection{Reservoirs for zoonotic HBV transmissions}

A worldwide eradication of human HBV would require the following prerequisites: first of all, a better protection from infection by an even more effective vaccine in combination with improved hygiene practices, and second the de facto cure of the many millions of chronically HBV-infected people as a source of infection. Last but not least, much stricter wildlife protection measures to reduce humanape-contacts will be necessary both to save our closest relatives from extinction and to protect ourselves from viral reintroduction (e.g. via "bush meat"). As noted above, it should be considered that based on genetic classification, one single HBV species contains all viral isolates endemic in hominoids, including all human HBV genotypes and HBV isolates from apes (chimpanzee, gorilla, orangutan, and gibbon). Although hepadnaviral infections are regarded as highly host-specific, 
interspecies transmission events of different HBV genotypes between members of the superfamily Hominoidea can be deduced from phylogenetic data. Interspecies transmission of the two New World primate hepadnavirus species, WMHBV isolated from woolly monkeys (Lanford et al., 1998) and CMHBV from capuchin monkeys (de Carvalho Dominguez Souza et al., 2018), have not yet been described but are most likely, too. Efficient experimental infection with WMHBV has been described in spider monkeys (Lanford et al., 1998) which are closely related to woolly monkeys. No such experimental in vivo data are available for CMHBV, but in vitro data have shown that CMHBV surface proteins can specifically interact with homologues of the HBV entry receptor sodium-taurocholate cotransporting polypeptide (NTCP), from closely related monkey species (de Carvalho Dominguez Souza et al., 2018). Interestingly, CMHBV surface proteins are also able to specifically interact with the (human) hNTCP and support infection of human hepatocytes via hNTCP (de Carvalho Dominguez Souza et al., 2018). So far, TBHBV from the tent-making bat Uroderma bilobatum is the only known non-primate hepadnavirus whose surface proteins interact very efficiently with hNTCP and can also infect primary human hepatocytes in vitro (Drexler et al., 2013). The most worrying aspect is that although CMHBV infection of human hepatocytes could be neutralized in vitro by high doses of antiHBs (> 500 IU/L) from successfully vaccinated individuals (de Carvalho Dominguez Souza et al., 2018), this was not possible for TBHBV infections due to the many amino acid exchanges in the antigenic determinant of the surface proteins compared to the HBV vaccine (Drexler et al., 2013). In summary, primates harbor a reservoir of hepadnaviruses with varying zoonotic potential. The only non-primate animals that carry hepadnaviruses with known zoonotic potential are from the large and diverse order of bats (Chiroptera). Further investigations are necessary to characterize the full zoonotic potential of the many newly discovered hepadnaviruses in bats.

\section{Impact of HBV genetic variability for development of vaccines and antiviral therapy}

\subsection{The HBV surface proteins}


The three co-carboxy-terminal HBV surface proteins L-, M- and SHBs, encoded by a single ORF (Figure 1), can be distinguished by amino-terminal polypeptide extensions (PreS1+PreS2) and co- and posttranslational modifications (Glebe and Bremer, 2013). The shared S domain encompasses 226 aa (Figure 5). The amino-terminal extensions to SHBs are the PreS1 domain (present only in LHBs) and the PreS2 domain (present in L- and MHBs). Across all wildtype HBV genotypes known so far, the number of aa residues of SHBs and the PreS2 domain (55 aa) is constant, while the PreS1 domain of LHBs shows genotypic variations of either 109, 118 or 119 residues (Figure 5) (Glebe and Bremer, 2013; Kramvis, 2014). The HBV surface proteins are translated from two viral mRNA species with different 5' ends. The longer mRNA (2.4 kb) exclusively facilitates synthesis of LHBs, while M- and SHBs are both translated from a single shorter mRNA species (2.1 kb) (Glebe and Bremer, 2013). Transcription of these two HBV mRNAs is driven by different viral promoter/enhancer systems, thus allowing independent regulation of transcription and thus differential intracellular expression levels of LHBs versus M- and SHBs (Cattaneo et al., 1983; Raney et al., 1991). This is important because an intracellular imbalance in favor of LHBs towards the amount of M- and SHBs can lead to adverse effects in the cell, such as endoplasmic reticulum (ER) stress, which can trigger cellular signals for apoptosis or uncontrolled cellular growth (Montalbano et al., 2016).

\subsection{The S domain of HBV surface proteins and its antigenic loop}

The $\mathrm{S}$ domain is translated at the ER with integration of four hydrophobic transmembrane domains (TM-I-IV) into the ER membrane (Figure 5). Stability of SHBs is provided by formation of intra- and intermolecular disulfide bridges between cysteines in the lumen of the ER, resulting in formation of a 60 aa long external antigenic loop (AGL, aa 99-160) between TM-II and TM-III that carries the major antigenic determinant (called $a$-determinant) of the viral surface (Glebe and Bremer, 2013). The hydrophilicity of this domain is partly increased by $\mathrm{N}$-glycosylation at the highly conserved residue Asn146, but only about half of the synthesized protein molecules are finally glycosylated at this site 
(Seitz et al., 2020). During translation of LHBs and MHBs, their C-terminal S domains are produced in a similar manner. Intermolecular disulfide bridging between the $\mathrm{S}$ domains of LHBs, MHBs, and SHBs leads to formation of protein homo- and heterodimers (Suffner et al., 2018) that in turn selfassemble to form SVP or budding virions (Ning et al., 2018) which become actively secreted from infected hepatocytes without cellular lysis (Blondot et al., 2016). The numerous intra- and intermolecular disulfide bonds within the S domains (Suffner et al., 2018) contribute to the wellknown structural stability of SVP and virions and are one of the reasons for the high resistance of HBV to inactivation by dehydration and heat stress (Kobayashi et al., 1984; Konig et al., 2019). The molecular basis of this stability, exceeding that of most other enveloped viruses, is mainly determined by eight cysteines within the external loop of the $\mathrm{S}$ domain. The high cysteine density in this region is conserved within the genus Orthohepadnavirus and a feature shared with the piscine metahepadnaviruses (Lauber et al., 2017). Exchange of these cysteines by mutagenesis leads to severe impairment of the conformation of the S domain (Mangold et al., 1997) with a reduced budding competence and infectivity of virions (Abou-Jaoude and Sureau, 2007).

\subsection{HBV-Vaccines and Vaccine-approaches}

The starting biomaterials for the first active HBV vaccines were extracted directly from plasma of chronically HBV-infected patients (for reviews, see: Gerlich, 2015; Huzair and Sturdy, 2017). However, it was not the virions that were utilized by the vaccine manufacturers, but the noninfectious SVP present in huge excess in carrier plasma. These SVP can be separated quite easily from the virions by biophysical methods. Subsequent processing, such as inactivation of remaining viruses and adjuvantation, resulted in safe and immunogenic first-generation HBV vaccines that provided protection against acute and chronic hepatitis B, based on initial clinical trials in high-risk groups (Buynak et al., 1976; Maupas et al., 1976; Szmuness et al., 1980; Thomssen et al., 1982). The cloning of the HBV genome enabled the large-scale production of SVP in recombinant yeast cells, and the 
corresponding yeast-derived second-generation vaccines showed comparable protection against HBV as plasma-derived vaccines in early clinical trials (McMahon, Wainwright, 1993). The global use of these vaccines to immunize infants, adolescents and special risk groups has been instrumental in reducing new $\mathrm{HBV}$ infections, and thus the global incidence of acute/chronic $\mathrm{HB}$ and its sequelae liver cirrhosis and HCC (Gerlich, 2015). While vaccine response rates with yeast-derived vaccines are excellent in healthy infants and adolescents (> 99\%), they are insufficient in about $5 \%$ of healthy adults. The rate of non-responders can rise to $70 \%$ in certain groups of people with pre-existing lifestyle/medical problems or conditions of a lowered immune competence (Gerlich, 2015). For historical reasons, the vast majority of yeast-derived vaccines consist only of the SHBs of the globally underrepresented HBV genotype A2, which is dominant only in Northern Europe and North America. Nevertheless, it also protects against infections with other genotypes, although well-documented clinical cases of breakthrough infections with genetically very distant genotypes (e.g. F) despite prior successful vaccination have been reported (Luongo et al., 2015; O'Halloran et al., 2011; Tacke et al., 2007). The underlying problem with these incidences of vaccine escape is that a predominant fraction of the immune response to the vaccine is subtype-specific. With high anti-HBs titers $(>1,000$ $\mathrm{IU} / \mathrm{L})$, this may be irrelevant, but low or waning anti-HBs-titers over time increase the risk of breakthrough infection with antigenically distant HBV genotypes. This problem was also evident in studies on newly acquired HBV infections of healthy American blood donors (Stramer et al., 2011). The frequencies of breakthrough infections among those vaccinated blood donors were significantly higher for HBV genotypes B, C, D and F and at anti-HBs titers of less than $100 \mathrm{IU} / \mathrm{L}$. However, all nonvaccinated, freshly infected individuals observed in this study had acquired HBV subgenotype $A 2$, the predominant variant in the USA (Stramer et al., 2011). Although all infections described in this study had been asymptomatic and transient, this still poses a threat to blood safety due to the very high infectivity of HBV. Recent calculations of the minimal infectious dose of HBV are as low as 16 virions (calculated as HBV genomes, or 3 International Units, IU), following accidental transmission through HBV-contaminated blood transfusions (Candotti et al., 2019). 


\section{Mutations affecting antigenicity and vaccine-escape}

A single amino acid exchange (G145R) within the $a$-determinant/AGL of the $S$ domain (Figure 5 ) was one of the first HBV variants found to be associated with breakthrough infections in newborns from chronically infected mothers, despite the combined active/passive vaccination directly after birth (Gerlich, 2015). The obvious concern that this immune-escape variant could spread efficiently in a population of fully vaccinated individuals turned out to be negligible given that the anti-HBs titers in the population are sufficiently high: Successfully vaccinated chimpanzees with high anti-HBs titers were protected against infection with variant G145R (Ogata et al., 1999). Notably, many other immune escape mutations have been identified and characterized since then. For an extended overview of the genetic variability of HBV immune escape variants see also: (Rajoriya et al., 2017; Tong and Revill, 2016).

\section{Emergence of vaccine-escape mutations during specific antiviral therapy}

Due to the overlapping ORFs of $\mathrm{P}$ and $\mathrm{S}$ (Figure $1 \mathrm{C}$ ), adaptive mutations within the RT domain positively selected under therapy with nucleoside/nucleotide analogues (NA) may concomitantly lead to non-synonymous substitutions of corresponding codon positions in the S-ORF (Torresi, 2002). The development of specific mutations within the $a$-determinant was indeed observed during NA therapy of chronic HBV carriers; vaccine-escape mutations occurred in particular when lamivudine was used, even when patients were not treated with anti-HBs (Colagrossi et al., 2018). The individual mutations in the S-ORF not only led to specific amino acid exchanges in the a-determinant/AGL (Figure 5) but sometimes also to C-terminally shortened surface proteins resulting from introduction of a stop codon in the S-ORF, which leads to premature translation termination (Colledge et al., 2017). Misfolded, C-terminally truncated forms of HBs are associated with the development of HCC in transgenic mice. It is mediated by direct transcriptional activation through an altered intracellular 
topology of the PreS domains of L- and MHBs (Hildt et al., 2002). However, more clinical studies are needed to determine whether these effects observed in mice also manifest themselves in chronically HBV-infected patients. Furthermore, the observed intracellular retention and accumulation of these variants within the infected cell can contribute to ER stress and apoptosis (Colledge et al., 2017; Warner and Locarnini, 2008). Notably, the occurrence of such mutants remains underdiagnosed, since secretion not only of virions but also of SVP is inhibited which may result in detection of low or no HBsAg in the serum of affected chronic carriers. The relevant mutations have been frequently described under therapy with NA that have a low genetic barrier (e.g. lamivudine, adefovir) and often led to therapy breakthroughs (Colagrossi et al., 2018; Colledge et al., 2017; Torresi, 2002). The use of recommended NA with improved efficacy and higher genetic barrier (e.g. tenofovir, entecavir) should reduce the occurrence of these dangerous escape mutants during therapy.

\subsection{The PreS1 domain of LHBs determines viral infectivity of HBV}

LHBs is the key player for viral envelopment and infectivity (for reviews, see: Glebe and Bremer, 2013; Seitz et al., 2020). While the C-terminal part of PreS1 (extending into the first 5 aa of PreS2) is necessary for envelopment of cytosolic mature core particles during viral budding (Bruss, 1997), the high-affinity virus-receptor binding sites of primate HBV reside in the $\mathrm{N}$-terminal part (Figure 5). During budding, the PreS1/PreS2 domains of LHBs have an entirely inward (cytosolic) orientation facilitating contact with core particles. Consequently, newly secreted virions are functional immature and non-infectious (i.e. not-yet-infectious) due to the absence of PreS1 on the particle surface (Seitz et al., 2020; Seitz et al., 2016). The subsequent topological switch of the PreS domains across the viral membrane onto the outside leads to receptor binding competence, thus rendering the virions infectious. This distinct maturation process initiates spontaneously in virions circulating in the blood stream and proceeds within the particle population with a half-time of $4.7 \mathrm{~h}$ (Seitz et al., 2020; Seitz et al., 2016). 
The infection-determining regions for high-affinity binding to the liver-specific HBV uptake receptor NTCP are located within the N-terminal 75 amino acids of the PreS1 domain (Figure 5) (for reviews, see: Glebe and Bremer, 2013; Glebe and Urban, 2007; Seitz et al., 2020). A short and highly conserved motif within this determinant (NPLGFFP at aa position 9-15 in genotype D) together with the $\mathrm{N}$-terminal myristoylation at glycine 2 have been shown to be essential for the infection process (Figure 5). This motif is conserved between HBV, the two related viral species from New World monkeys and some isolates from bats (Drexler et al., 2013).

\subsection{Antivirals interfering with the early HBV infection process by targeting PreS1}

Since the PreS1 domain of LHBs is a central driver of infectivity, many antiviral approaches have been taken to attack its key function in viral entry. These can be divided into two categories: disruption of the virus-receptor interaction by (1) neutralizing antibodies against PreS1, and (2) by blocking of the viral binding sites on NTCP.

\section{Neutralizing antibodies against PreS1}

Various anti-PreS1-antibodies have been successfully used to neutralize infection in vitro and in vivo. Most of them target epitopes located at a rather N-terminal part of PreS1 between aa 19-48 (Glebe, 2006; Glebe and Urban, 2007). However, there are known genotypic variations in this region that might reduce a broad-spectrum neutralizing efficacy of such monoclonal antibodies (Bremer et al., 2011; Glebe et al., 2003). On the other hand, the central receptor binding motif NPLGFFP at PreS1 aa 9-15 (Figure 5) is highly conserved between all three primate and some bat hepadnavirus species (Drexler et al., 2013) and single amino acid changes within this small stretch abolish HBV infectivity completely (Engelke et al., 2006). This motif could therefore be considered the Achilles' heel of the virus because specific antibodies against this particular sequence should be highly efficient in neutralizing hepadnaviral infections across all primate and bat species. The study of Bremer et al. 
tested this hypothesis by generating polyclonal antisera against specific polypeptide stretches of PreS1 (Bremer et al., 2011). As expected, polyclonal antisera against the $\mathrm{N}$-terminal (aa 2-48) and the C-terminal region (aa 78-108) showed broad reactivity against all HBV genotypes tested (A, C, D), including genotype $\mathrm{F}$ that is most distinct to all others with regard to the PreS1 sequence. However, only antisera against the $\mathrm{N}$-terminal domain showed neutralizing activity (Figure 5). Interestingly, antisera generated against aa residues $2-21$, containing the very essential receptor binding motif showed neither reactivity against SVP or virions purified from human sera, nor neutralizing activity during HBV infection in vitro (Bremer et al., 2011). Subsequent analyses with chemically synthesized PreS1-peptides demonstrated that the $\mathrm{N}$-terminal myristoylation at glycine-2 prevented antibody recognition of the receptor binding motif. It turned out that it is not specifically the added myristoyl moiety itself decreasing antibody binding, but simply the increased hydrophobicity: The reactivity of the neutralizing antisera inversely correlated with the length of the carbon chain (C) artificially added to the $\mathrm{N}$ terminus of the synthetic peptides ranging from pentanoyl (C5) to the natural myristoyl (C14). Thus, although the receptor binding motif at aa residues 9-15 is immunogenic in principle, antibodies directed against this structure likely cannot reach it on the viral particle surface under natural conditions (Bremer et al., 2011). Nevertheless, anti-PreS1 antibodies targeting the downstream aa residues $19-48$ are usually superior to anti-HBs antibodies in the prevention of HBV infection (Glebe et al., 2003), because they are directly interfering with the PreS1-dependent interaction of the virus with NTCP (Figure 5). However, amino acid variations within this domain between HBV genotypes have to be considered carefully during generation of highly cross-reactive anti-PreS1-antisera (Bremer et al., 2011).

\section{Blocking of the viral binding sites on the cellular HBV-receptor NTCP}

The importance of the first 75 aa of PreS1 for viral entry (Figure 5) was known before the discovery of the cellular bile-acid transporter NTCP as the high affinity HBV uptake receptor (for reviews, see: 
Glebe and Bremer, 2013; Glebe and Urban, 2007). The use of highly efficient infection-interfering myristoylated PreS1-peptides of variable length led to the characterization of infection-relevant essential (aa 9-15) and accessory motifs (aa 19-48) within LHBs (Figure 5) (Glebe et al., 2005; Gripon et al., 2005; Gripon et al., 2002, Petersen et al., 2008). These peptides were not only crucial to identify the viral infection determinants, but also led to the discovery and characterization of the NTCP receptor (Yan et al., 2012) and paved the way for developing specific HBV entry inhibitors. Due to the high degree of conservation and the essentiality of the respective amino acid sequence in all currently known HBV genotypes, it is very unlikely that naturally occurring viral mutants will undermine the antiviral effect of these highly active peptides.

As an alternative to acylated peptides, allosteric small molecule HBV-entry inhibitors targeting NTCP have been evaluated. These lead structures comprise natural substrates (bile acids) or derivatives thereof, or synthetic NTCP substrates (e.g. ezetimibe, irbesartan) that either block binding of HBV, inactivate NTCP or interfere with cellular NTCP re-uptake (for a review, see: Tu and Urban, 2018).

\subsection{Antivirals interfering with reverse transcription and replication of HBV}

Direct acting antivirals are nucleoside/nucleotide analogues (NA) that specifically interfere with HBV replication in infected cells by acting on reverse transcription and/or the DNA-dependent DNA synthesis activity of the HBV polymerase (for a review, see: Zoulim and Locarnini, 2009). Currently approved first line drugs are entecavir (ETV), a deoxyguanosine analogue and the deoxyadenine analogue tenofovir (TDF) including its variant form tenofovir alafenamide (TAF). They are highly effective in significantly lowering viremia virtually down to negativity upon long term treatment of chronic HB (CHB) patients. They have a favorable oral administration route and usually good tolerability with minor side effects. In many cases they have to be taken lifelong, since NA do not directly interfere with the stability of the viral covalently closed circular DNA (cccDNA) persisting as an episome in the nucleus of the host cell (for a review, see: Buti et al., 2018). Nevertheless, years 
after continuous antiviral treatment with NA, a decline of the cccDNA levels in the liver can often be observed (Lai et al., 2017). In summary ETV and TDF/TAF efficiently interfere with HBV replication of all present HBV genotypes, because the functional features of the hepadnaviral polymerase are highly conserved within the family of hepadnaviruses.

\section{Conclusions}

$\mathrm{HBV}$ is a genetically diverse virus species composed of 10 extant genotypes and several extinct genotypes that affected historic human populations in the past. Being present in humans and other apes, its origin can be traced back to several million years into the past using molecular phylogenetics approaches and genome-based comparison with related hepadnaviruses infecting diverse vertebrate species. The strong host association and correspondingly low rate of hepadnavirus evolution at the macroevolutionary scale is in stark contrast to high rates of HBV evolution within infected individuals. Diversification of these "adaptors" under pressure of the host immune system poses various challenges for vaccine and antiviral development including the emergence of resistance-conferring substitutions that might be genotype-specific.

Full eradication of HBV appears intractable at the moment due to different reasons. These include a viral source in chronic HBV carriers that together constitute a significant portion of the human population as well as a natural reservoir in apes. Moreover, closely related hepadnavirus species in New World monkeys and diverse bats represent a potential risk for zoonotic spillover infections into humankind. Additional problems are posed by the poor or absent responsiveness and waning antibody titers in a subset of vaccinees. Future research efforts should thus focus on the improvement of vaccines and the development of effective antivirals. In addition, medical surveillance systems have to be established to interrupt the globally predominant vertical mother-toinfant transmission route. For any such effort a focus should be put on low-income and developing countries that suffer most from the high burden of HBV prevalence. 


\section{Acknowledgments}

We thank Ben Krause-Kyora (University Kiel) and Johannes Krause (Max-Planck-Institute Jena) for providing the nucleotide alignment on which Figure 3 is based on. S.S. acknowledges funding by the Deutsche Forschungsgemeinschaft (DFG, German Research Foundation) for project TP23N within TRR 179. D.G. was supported by grants B08/SFB1021 and GL595/9-1 from the DFG. The National Reference Centre for Hepatitis B Viruses and Hepatitis D Viruses at Justus Liebig University Giessen is supported by the German Ministry of Health via the Robert Koch Institute, Berlin. CL is supported by the DFG through the Cluster of Excellence RESIST (EXC 2155), project 390874280.

\section{References}

Abou-Jaoude, G., Sureau, C., 2007. Entry of hepatitis delta virus requires the conserved cysteine residues of the hepatitis $B$ virus envelope protein antigenic loop and is blocked by inhibitors of thioldisulfide exchange. J Virol 81, 13057-13066.

Aghazadeh, M., Shi, M., Barrs, V.R., McLuckie, A.J., Lindsay, S.A., Jameson, B., Hampson, B., Holmes, E.C., Beatty, J.A., 2018. A Novel Hepadnavirus Identified in an Immunocompromised Domestic Cat in Australia. Viruses 10.

Araujo, N.M., 2015. Hepatitis B virus intergenotypic recombinants worldwide: An overview. Infect. Genet. Evol 36, 500-510.

Bartenschlager, R., Schaller, H., 1988. The amino-terminal domain of the hepadnaviral P-gene encodes the terminal protein (genome-linked protein) believed to prime reverse transcription. EMBO J 7, 4185-4192.

Begun, D.R., 2003. Planet of the apes. Sci. Am 289, 74-83.

Blondot, M.L., Bruss, V., Kann, M., 2016. Intracellular transport and egress of hepatitis B virus. J Hepatol 64, S49-S59.

Bohme, M., Spassov, N., Fuss, J., Troscher, A., Deane, A.S., Prieto, J., Kirscher, U., Lechner, T., Begun, D.R., 2019. A new Miocene ape and locomotion in the ancestor of great apes and humans. Nature 575, 489-493.

Bollyky, P.L., Rambaut, A., Harvey, P.H., Holmes, E.C., 1996. Recombination between sequences of hepatitis B virus from different genotypes. J Mol. Evol 42, 97-102.

Böttcher, B., Wynne, S.A., Crowther, R.A., 1997. Determination of the fold of the core protein of hepatitis B virus by electron cryomicroscopy. Nature 386, 88-91.

Bremer, C.M., Sominskaya, I., Skrastina, D., Pumpens, P., El Wahed, A.A., Beutling, U., Frank, R., Fritz, H.J., Hunsmann, G., Gerlich, W.H., Glebe, D., 2011. N-terminal myristoylation-dependent masking of neutralizing epitopes in the preS1 attachment site of hepatitis B virus. J Hepatol 55, 29-37. 
Browning, S.R., Browning, B.L., Zhou, Y., Tucci, S., Akey, J.M., 2018. Analysis of Human Sequence Data Reveals Two Pulses of Archaic Denisovan Admixture. Cell 173, 53-61.

Bruss, V., 1997. A short linear sequence in the pre-S domain of the large hepatitis B virus envelope protein required for virion formation. J Virol 71, 9350-9357.

Buti, M., Riveiro-Barciela, M., Esteban, R., 2018. Long-term safety and efficacy of nucleo(t)side analogue therapy in hepatitis B. Liver Int 38 Suppl 1, 84-89.

Buynak, E.B., Roehm, R.R., Tytell, A.A., Bertland, A.U., 2nd, Lampson, G.P., Hilleman, M.R., 1976. Vaccine against human hepatitis B. JAMA 235, 2832-2834.

Candotti, D., Assennato, S.M., Laperche, S., Allain, J.P., Levicnik-Stezinar, S., 2019. Multiple HBV transfusion transmissions from undetected occult infections: revising the minimal infectious dose. Gut 68, 313-321.

Castelhano, N., Araujo, N.M., Arenas, M., 2017. Heterogeneous recombination among Hepatitis B virus genotypes. Infect. Genet. Evol 54, 486-490.

Cattaneo, R., Will, H., Hernandez, N., Schaller, H., 1983. Signals regulating hepatitis B surface antigen transcription. Nature 305, 336-338.

Chang, S.F., Netter, H.J., Bruns, M., Schneider, R., Frolich, K., Will, H., 1999. A new avian hepadnavirus infecting snow geese (Anser caerulescens) produces a significant fraction of virions containing singlestranded DNA. Virology 262, 39-54.

Colagrossi, L., Hermans, L.E., Salpini, R., Di Carlo, D., Pas, S.D., Alvarez, M., Ben-Ari, Z., Boland, G., Bruzzone, B., Coppola, N., Seguin-Devaux, C., Dyda, T., Garcia, F., Kaiser, R., Kose, S., Krarup, H., Lazarevic, I., Lunar, M.M., Maylin, S., Micheli, V., Mor, O., Paraschiv, S., Paraskevis, D., Poljak, M., Puchhammer-Stockl, E., Simon, F., Stanojevic, M., Stene-Johansen, K., Tihic, N., Trimoulet, P., Verheyen, J., Vince, A., Lepej, S.Z., Weis, N., Yalcinkaya, T., Boucher, C.A.B., Wensing, A.M.J., Perno, C.F., Svicher, V., research, H.w.g.o.t.E.S.f.t.a., 2018. Immune-escape mutations and stop-codons in HBsAg develop in a large proportion of patients with chronic HBV infection exposed to anti-HBV drugs in Europe. BMC Infect Dis 18, 251.

Colledge, D., Soppe, S., Yuen, L., Selleck, L., Walsh, R., Locarnini, S., Warner, N., 2017. Stop codons in the hepatitis $B$ surface proteins are enriched during antiviral therapy and are associated with host cell apoptosis. Virology 501, 70-78.

Conway, J.F., Cheng, N., Zlotnick, A., Wingfield, P.T., Stahl, S.J., Steven, A.C., 1997. Visualization of a 4helix bundle in the hepatitis B virus capsid by cryo-electron microscopy. Nature 386, 91-94.

Dane, D.S., Cameron, C.H., Briggs, M., 1970. Virus-like particles in serum of patients with Australiaantigen-associated hepatitis. Lancet 1, 695-698.

de Carvalho Dominguez Souza, B.F., Konig, A., Rasche, A., de Oliveira Carneiro, I., Stephan, N., Corman, V.M., Roppert, P.L., Goldmann, N., Kepper, R., Muller, S.F., Volker, C., de Souza, A.J.S., Gomes-Gouvea, M.S., Moreira-Soto, A., Stocker, A., Nassal, M., Franke, C.R., Rebello Pinho, J.R., Soares, M.D.C.P., Geyer, J., Lemey, P., Drosten, C., Netto, E.M., Glebe, D., Drexler, J.F., 2018. A novel hepatitis $B$ virus species discovered in capuchin monkeys sheds new light on the evolution of primate hepadnaviruses. J Hepatol 68, 1114-1122.

Dill, J.A., Camus, A.C., Leary, J.H., Di, G.F., Holmes, E.C., Ng, T.F., 2016. Distinct Viral Lineages from Fish and Amphibians Reveal the Complex Evolutionary History of Hepadnaviruses. J. Virol 90, 79207933.

Drexler, J.F., Geipel, A., Konig, A., Corman, V.M., van Riel, D., Leijten, L.M., Bremer, C.M., Rasche, A., Cottontail, V.M., Maganga, G.D., Schlegel, M., Muller, M.A., Adam, A., Klose, S.M., Carneiro, A.J., Stocker, A., Franke, C.R., Gloza-Rausch, F., Geyer, J., Annan, A., Adu-Sarkodie, Y., Oppong, S., Binger, T., Vallo, P., Tschapka, M., Ulrich, R.G., Gerlich, W.H., Leroy, E., Kuiken, T., Glebe, D., Drosten, C., 2013. Bats carry pathogenic hepadnaviruses antigenically related to hepatitis $B$ virus and capable of infecting human hepatocytes. Proc Natl Acad Sci U S A 110, 16151-16156.

Dryden, K.A., Wieland, S.F., Whitten-Bauer, C., Gerin, J.L., Chisari, F.V., Yeager, M., 2006. Native hepatitis B virions and capsids visualized by electron cryomicroscopy. Mol. Cell 22, 843-850.

Durvasula, A., Sankararaman, S., 2020. Recovering signals of ghost archaic introgression in African populations. Sci Adv 6, eaax5097. 
Engelke, M., Mills, K., Seitz, S., Simon, P., Gripon, P., Schnolzer, M., Urban, S., 2006. Characterization of a hepatitis B and hepatitis delta virus receptor binding site. Hepatology 43, 750-760.

Feschotte, C., Gilbert, C., 2012. Endogenous viruses: insights into viral evolution and impact on host biology. Nat. Rev. Genet 13, 283-296.

Gerlich, W.H., 2013. Medical virology of hepatitis B: how it began and where we are now. Virol J 10, 239.

Gerlich, W.H., 2015. Prophylactic vaccination against hepatitis B: achievements, challenges and perspectives. Med Microbiol Immunol 204, 39-55.

Gerlich, W.H., Glebe, D., Kramvis, A., Magnius, L.O., 2020. Peculiarities in the designations of hepatitis $B$ virus genes, their products, and their antigenic specificities: a potential source of misunderstandings. Virus Genes.

Gilbert, C., Feschotte, C., 2010. Genomic fossils calibrate the long-term evolution of hepadnaviruses. PLoS Biol 8.

Gilbert, C., Meik, J.M., Dashevsky, D., Card, D.C., Castoe, T.A., Schaack, S., 2014. Endogenous hepadnaviruses, bornaviruses and circoviruses in snakes. Proc Biol Sci 281, 20141122. Glebe, D., 2006. Attachment sites and neutralising epitopes of hepatitis B virus. Minerva Gastroenterol Dietol 52, 3-21.

Glebe, D., Aliakbari, M., Krass, P., Knoop, E.V., Valerius, K.P., Gerlich, W.H., 2003. Pre-s1 antigendependent infection of Tupaia hepatocyte cultures with human hepatitis B virus. J Virol 77, 95119521.

Glebe, D., Bremer, C.M., 2013. The molecular virology of hepatitis B virus. Semin Liver Dis 33, 103112.

Glebe, D., Urban, S., 2007. Viral and cellular determinants involved in hepadnaviral entry. World J Gastroenterol 13, 22-38.

Glebe, D., Urban, S., Knoop, E.V., Cag, N., Krass, P., Grun, S., Bulavaite, A., Sasnauskas, K., Gerlich, W.H., 2005. Mapping of the hepatitis B virus attachment site by use of infection-inhibiting preS1 lipopeptides and tupaia hepatocytes. Gastroenterology 129, 234-245.

Godoy, B.A., Alvarado-Mora, M.V., Gomes-Gouvea, M.S., Pinho, J.R., Fagundes, N., Jr., 2013. Origin of $\mathrm{HBV}$ and its arrival in the Americas--the importance of natural selection on time estimates. Antivir. Ther 18, 505-512.

Gogarten, J.F., Ulrich, M., Bhuva, N., Garcia, J., Jain, K., Lee, B., Lohrich, T., Oleynik, A., CouacyHymann, E., Fuh, N.T., Mishra, N., Briese, T., Calvignac-Spencer, S., Lipkin, W.I., Leendertz, F.H., 2019. A Novel Orthohepadnavirus Identified in a Dead Maxwell's Duiker (Philantomba maxwellii) in Tai National Park, Cote d'Ivoire. Viruses 11.

Green, R.E., Krause, J., Briggs, A.W., Maricic, T., Stenzel, U., Kircher, M., Patterson, N., Li, H., Zhai, W., Fritz, M.H., Hansen, N.F., Durand, E.Y., Malaspinas, A.S., Jensen, J.D., Marques-Bonet, T., Alkan, C., Prufer, K., Meyer, M., Burbano, H.A., Good, J.M., Schultz, R., Aximu-Petri, A., Butthof, A., Hober, B., Hoffner, B., Siegemund, M., Weihmann, A., Nusbaum, C., Lander, E.S., Russ, C., Novod, N., Affourtit, J., Egholm, M., Verna, C., Rudan, P., Brajkovic, D., Kucan, Z., Gusic, I., Doronichev, V.B., Golovanova, L.V., Lalueza-Fox, C., de la Rasilla, M., Fortea, J., Rosas, A., Schmitz, R.W., Johnson, P.L.F., Eichler, E.E., Falush, D., Birney, E., Mullikin, J.C., Slatkin, M., Nielsen, R., Kelso, J., Lachmann, M., Reich, D., Paabo, S., 2010. A draft sequence of the Neandertal genome. Science 328, 710-722.

Grethe, S., Heckel, J.O., Rietschel, W., Hufert, F.T., 2000. Molecular epidemiology of hepatitis B virus variants in nonhuman primates. J Virol 74, 5377-5381.

Gripon, P., Cannie, I., Urban, S., 2005. Efficient inhibition of hepatitis B virus infection by acylated peptides derived from the large viral surface protein. J Virol 79, 1613-1622.

Gripon, P., Rumin, S., Urban, S., Le Seyec, J., Glaise, D., Cannie, I., Guyomard, C., Lucas, J., Trepo, C., Guguen-Guillouzo, C., 2002. Infection of a human hepatoma cell line by hepatitis B virus. Proc Natl Acad Sci U S A 99, 15655-15660.

Guo, H., Mason, W.S., Aldrich, C.E., Saputelli, J.R., Miller, D.S., Jilbert, A.R., Newbold, J.E., 2005. Identification and characterization of avihepadnaviruses isolated from exotic anseriformes maintained in captivity. J Virol 79, 2729-2742. 
Hahn, C.M., Iwanowicz, L.R., Cornman, R.S., Conway, C.M., Winton, J.R., Blazer, V.S., 2015.

Characterization of a Novel Hepadnavirus in the White Sucker (Catostomus commersonii) from the Great Lakes Region of the United States. J Virol 89, 11801-11811.

Hammer, M.F., Woerner, A.E., Mendez, F.L., Watkins, J.C., Wall, J.D., 2011. Genetic evidence for archaic admixture in Africa. Proc Natl Acad Sci U S A 108, 15123-15128.

He, B., Fan, Q., Yang, F., Hu, T., Qiu, W., Feng, Y., Li, Z., Li, Y., Zhang, F., Guo, H., Zou, X., Tu, C., 2013 a. Hepatitis virus in long-fingered bats, Myanmar. Emerg. Infect. Dis 19, 638-640.

He, B., Li, Z., Yang, F., Zheng, J., Feng, Y., Guo, H., Li, Y., Wang, Y., Su, N., Zhang, F., Fan, Q., Tu, C., 2013b. Virome profiling of bats from Myanmar by metagenomic analysis of tissue samples reveals more novel Mammalian viruses. PLoS One 8, e61950.

Heermann, K.H., Goldmann, U., Schwartz, W., Seyffarth, T., Baumgarten, H., Gerlich, W.H., 1984. Large surface proteins of hepatitis B virus containing the pre-s sequence. J. Virol 52, 396-402.

Hildt, E., Munz, B., Saher, G., Reifenberg, K., Hofschneider, P.H., 2002. The PreS2 activator MHBs(t) of hepatitis $B$ virus activates c-raf-1/Erk2 signaling in transgenic mice. EMBO J 21, 525-535.

Hiller, T., Rasche, A., Brandel, S.D., Konig, A., Jeworowski, L., Teague, O.M.M., Cottontail, V., Page, R.A., Glebe, D., Drexler, J.F., Tschapka, M., 2019. Host Biology and Anthropogenic Factors Affect Hepadnavirus Infection in a Neotropical Bat. Ecohealth 16, 82-94.

Hu, X., Javadian, A., Gagneux, P., Robertson, B.H., 2001. Paired chimpanzee hepatitis B virus (ChHBV) and mtDNA sequences suggest different ChHBV genetic variants are found in geographically distinct chimpanzee subspecies. Virus Res 79, 103-108.

Huzair, F., Sturdy, S., 2017. Biotechnology and the transformation of vaccine innovation: The case of the hepatitis B vaccines 1968-2000. Stud. Hist Philos. Biol Biomed. Sci 64, 11-21.

Jo, W.K., Pfankuche, V.M., Petersen, H., Frei, S., Kummrow, M., Lorenzen, S., Ludlow, M., Metzger, J., Baumgartner, W., Osterhaus, A., van, d., V, 2017. New Avian Hepadnavirus in Palaeognathous Bird, Germany. Emerg. Infect. Dis 23, 2089-2091.

Kahila Bar-Gal, G., Kim, M.J., Klein, A., Shin, D.H., Oh, C.S., Kim, J.W., Kim, T.H., Kim, S.B., Grant, P.R., Pappo, O., Spigelman, M., Shouval, D., 2012. Tracing hepatitis B virus to the 16th century in a Korean mummy. Hepatology 56, 1671-1680.

Kobayashi, H., Tsuzuki, M., Koshimizu, K., Toyama, H., Yoshihara, N., Shikata, T., Abe, K., Mizuno, K., Otomo, N., Oda, T., 1984. Susceptibility of hepatitis B virus to disinfectants or heat. J Clin Microbiol 20, 214-216.

Konig, A., Than, T.T., Todt, D., Yoon, S.K., Steinmann, J., Steinmann, E., Windisch, M.P., 2019. High tolerance of hepatitis B virus to thermal disinfection. J Hepatol 71, 1249-1251.

Kramvis, A., 2014. Genotypes and genetic variability of hepatitis B virus. Intervirology 57, 141-150. Kramvis, A., Kostaki, E.G., Hatzakis, A., Paraskevis, D., 2018. Immunomodulatory Function of HBeAg Related to Short-Sighted Evolution, Transmissibility, and Clinical Manifestation of Hepatitis B Virus. Front Microbiol 9, 2521.

Krause-Kyora, B., Susat, J., Key, F.M., Kuhnert, D., Bosse, E., Immel, A., Rinne, C., Kornell, S.C., Yepes, D., Franzenburg, S., Heyne, H.O., Meier, T., Losch, S., Meller, H., Friederich, S., Nicklisch, N., Alt, K.W., Schreiber, S., Tholey, A., Herbig, A., Nebel, A., Krause, J., 2018. Neolithic and medieval virus genomes reveal complex evolution of hepatitis $B$. Elife 7.

Lai, C.L., Wong, D., Ip, P., Kopaniszen, M., Seto, W.K., Fung, J., Huang, F.Y., Lee, B., Cullaro, G., Chong, C.K., Wu, R., Cheng, C., Yuen, J., Ngai, V., Yuen, M.F., 2017. Reduction of covalently closed circular DNA with long-term nucleos(t)ide analogue treatment in chronic hepatitis B. J Hepatol 66, 275-281. Lanford, R.E., Chavez, D., Brasky, K.M., Burns, R.B., III, Rico-Hesse, R., 1998. Isolation of a hepadnavirus from the woolly monkey, a New World primate. Proc Natl Acad Sci U S A 95, 57575761.

Lauber, C., Seitz, S., Mattei, S., Suh, A., Beck, J., Herstein, J., Borold, J., Salzburger, W., Kaderali, L., Briggs, J.A.G., Bartenschlager, R., 2017. Deciphering the Origin and Evolution of Hepatitis B Viruses by Means of a Family of Non-enveloped Fish Viruses. Cell Host. Microbe 22, 387-399. 
Lei, S.C., Xiao, X., Liu, J.W., Han, H.J., Gong, X.Q., Zhao, M., Wang, L.J., Qin, X.R., Yu, X.J., 2019. High prevalence and genetic diversity of hepatitis $B$ viruses in insectivorous bats from China. Acta Trop 199, 105130.

Leistner, C.M., Gruen-Bernhard, S., Glebe, D., 2008. Role of glycosaminoglycans for binding and infection of hepatitis B virus. Cell Microbiol 10, 122-133.

Lin, Y.Y., Liu, C., Chien, W.H., Wu, L.L., Tao, Y., Wu, D., Lu, X., Hsieh, C.H., Chen, P.J., Wang, H.Y., Kao, J.H., Chen, D.S., 2015. New insights into the evolutionary rate of hepatitis $B$ virus at different biological scales. J. Virol 89, 3512-3522.

Littlejohn, M., Locarnini, S., Yuen, L., 2016. Origins and Evolution of Hepatitis B Virus and Hepatitis D Virus. Cold Spring Harb. Perspect. Med 6, a021360.

Luongo, M., Critelli, R., Grottola, A., Gitto, S., Bernabucci, V., Bevini, M., Vecchi, C., Montagnani, G., Villa, E., 2015. Acute hepatitis B caused by a vaccine-escape HBV strain in vaccinated subject:

sequence analysis and therapeutic strategy. J Clin Virol 62, 89-91.

Lyons, S., Sharp, C., LeBreton, M., Djoko, C.F., Kiyang, J.A., Lankester, F., Bibila, T.G., Tamoufe, U., Fair, J., Wolfe, N.D., Simmonds, P., 2012. Species association of hepatitis B virus (HBV) in non-human apes; evidence for recombination between gorilla and chimpanzee variants. PLoS One 7, e33430. MacDonald, D.M., Holmes, E.C., Lewis, J.C., Simmonds, P., 2000. Detection of hepatitis B virus infection in wild-born chimpanzees (Pan troglodytes verus): phylogenetic relationships with human and other primate genotypes. J Virol 74, 4253-4257.

Magiorkinis, E.N., Magiorkinis, G.N., Paraskevis, D.N., Hatzakis, A.E., 2005. Re-analysis of a human hepatitis $B$ virus (HBV) isolate from an East African wild born Pan troglodytes schweinfurthii: evidence for interspecies recombination between HBV infecting chimpanzee and human. Gene 349, 165-171.

Mangold, C.M., Unckell, F., Werr, M., Streeck, R.E., 1997. Analysis of intermolecular disulfide bonds and free sulfhydryl groups in hepatitis B surface antigen particles. Arch Virol 142, 2257-2267.

Marion, P.L., Oshiro, L.S., Regnery, D.C., Scullard, G.H., Robinson, W.S., 1980. A virus in Beechey ground squirrels that is related to hepatitis B virus of humans. Proc Natl Acad Sci U S A 77, 29412945.

Mason, W.S., Seal, G., Summers, J., 1980. Virus of Pekin ducks with structural and biological relatedness to human hepatitis $B$ virus. J Virol 36, 829-836.

Maupas, P., Goudeau, A., Coursaget, P., Drucker, J., Bagros, P., 1976. Immunisation against hepatitis $B$ in man. Lancet 1, 1367-1370.

Meyer, M., Kircher, M., Gansauge, M.T., Li, H., Racimo, F., Mallick, S., Schraiber, J.G., Jay, F., Prufer, K., de, F.C., Sudmant, P.H., Alkan, C., Fu, Q., Do, R., Rohland, N., Tandon, A., Siebauer, M., Green, R.E., Bryc, K., Briggs, A.W., Stenzel, U., Dabney, J., Shendure, J., Kitzman, J., Hammer, M.F., Shunkov, M.V., Derevianko, A.P., Patterson, N., Andres, A.M., Eichler, E.E., Slatkin, M., Reich, D., Kelso, J., Paabo, S., 2012. A high-coverage genome sequence from an archaic Denisovan individual. Science 338, $222-$ 226.

Minarovits, J., Niller, H.H., 2019. Truncated oncoproteins of retroviruses and hepatitis B virus: A lesson in contrasts. Infect. Genet. Evol 73, 342-357.

Mizokami, M., Orito, E., 1999. Molecular evolution of hepatitis viruses. Intervirology 42, 159-165. Montalbano, R., Honrath, B., Wissniowski, T.T., Elxnat, M., Roth, S., Ocker, M., Quint, K., Churin, Y., Roederfeld, M., Schroeder, D., Glebe, D., Roeb, E., Di Fazio, P., 2016. Exogenous hepatitis B virus envelope proteins induce endoplasmic reticulum stress: involvement of cannabinoid axis in liver cancer cells. Oncotarget 7, 20312-20323.

Morozov, V., Pisareva, M., Groudinin, M., 2000. Homologous recombination between different genotypes of hepatitis B virus. Gene 260, 55-65.

Muhlemann, B., Jones, T.C., Damgaard, P.B., Allentoft, M.E., Shevnina, I., Logvin, A., Usmanova, E., Panyushkina, I.P., Boldgiv, B., Bazartseren, T., Tashbaeva, K., Merz, V., Lau, N., Smrcka, V., Voyakin, D., Kitov, E., Epimakhov, A., Pokutta, D., Vicze, M., Price, T.D., Moiseyev, V., Hansen, A.J., Orlando, L., Rasmussen, S., Sikora, M., Vinner, L., Osterhaus, A.D.M.E., Smith, D.J., Glebe, D., Fouchier, R.A.M., 
Drosten, C., Sjogren, K.G., Kristiansen, K., Willerslev, E., 2018. Ancient hepatitis B viruses from the Bronze Age to the Medieval period. Nature 557, 418-423.

Nie, F.Y., Lin, X.D., Hao, Z.Y., Chen, X.N., Wang, Z.X., Wang, M.R., Wu, J., Wang, H.W., Zhao, G., Ma, R.Z., Holmes, E.C., Zhang, Y.Z., 2018. Extensive diversity and evolution of hepadnaviruses in bats in China. Virology 514, 88-97.

Nie, F.Y., Tian, J.H., Lin, X.D., Yu, B., Xing, J.G., Cao, J.H., Holmes, E.C., Ma, R.Z., Zhang, Y.Z., 2019. Discovery of a highly divergent hepadnavirus in shrews from China. Virology 531, 162-170.

Ning, X., Luckenbaugh, L., Liu, K., Bruss, V., Sureau, C., Hu, J., 2018. Common and Distinct Capsid and Surface Protein Requirements for Secretion of Complete and Genome-Free Hepatitis B Virions. J Virol 92.

Njouom, R., Mba, S.A., Nerrienet, E., Foupouapouognigni, Y., Rousset, D., 2010. Detection and characterization of hepatitis $B$ virus strains from wild-caught gorillas and chimpanzees in Cameroon, Central Africa. Infect. Genet. Evol 10, 790-796.

Noppornpanth, S., Haagmans, B.L., Bhattarakosol, P., Ratanakorn, P., Niesters, H.G.M., Osterhaus, A.D.M.E., Poovorawan, Y., 2003. Molecular epidemiology of gibbon hepatitis B virus transmission. J Gen Virol 84, 147-155.

O'Halloran, J.A., De Gascun, C.F., Dunford, L., Carr, M.J., Connell, J., Howard, R., Hall, W.W., Lambert, J.S., 2011. Hepatitis B virus vaccine failure resulting in chronic hepatitis B infection. J Clin Virol 52, 151-154.

O'Hara, G.A., McNaughton, A.L., Maponga, T., Jooste, P., Ocama, P., Chilengi, R., Mokaya, J., Liyayi, M.I., Wachira, T., Gikungi, D.M., Burbridge, L., O'Donnell, D., Akiror, C.S., Sloan, D., Torimiro, J., Yindom, L.M., Walton, R., Andersson, M., Marsh, K., Newton, R., Matthews, P.C., 2017. Hepatitis B virus infection as a neglected tropical disease. PLoS Negl. Trop. Dis 11, e0005842.

Ogata, N., Cote, P.J., Zanetti, A.R., Miller, R.H., Shapiro, M., Gerin, J., Purcell, R.H., 1999. Licensed recombinant hepatitis $B$ vaccines protect chimpanzees against infection with the prototype surface gene mutant of hepatitis B virus. Hepatology 30, 779-786.

Orito, E., Mizokami, M., Ina, Y., Moriyama, E.N., Kameshima, N., Yamamoto, M., Gojobori, T., 1989. Host-independent evolution and a genetic classification of the hepadnavirus family based on nucleotide sequences. Proc. Natl. Acad. Sci. U. S. A 86, 7059-7062.

Patel, M.R., Emerman, M., Malik, H.S., 2011. Paleovirology - ghosts and gifts of viruses past. Curr. Opin. Virol 1, 304-309.

Patterson, R.Z., Klunk, J., Fornaciari, G., Giuffra, V., Duchene, S., Duggan, A.T., Poinar, D., Douglas, M.W., Eden, J.S., Holmes, E.C., Poinar, H.N., 2018. The paradox of HBV evolution as revealed from a 16th century mummy. PLoS Pathog 14, e1006750.

Petersen, J., Dandri, M., Mier, W., Lutgehetmann, M., Volz, T., von Weizsacker, F., Haberkorn, U., Fischer, L., Pollok, J.M., Erbes, B., Seitz, S., Urban, S., 2008. Prevention of hepatitis B virus infection in vivo by entry inhibitors derived from the large envelope protein. Nat Biotechnol 26, 335-341.

Piasecki, T., Kurenbach, B., Chrzastek, K., Bednarek, K., Kraberger, S., Martin, D.P., Varsani, A., 2012. Molecular characterisation of an avihepadnavirus isolated from Psittacula krameri (ring-necked parrot). Arch Virol 157, 585-590.

Prassolov, A., Hohenberg, H., Kalinina, T., Schneider, C., Cova, L., Krone, O., Frolich, K., Will, H., Sirma, H., 2003. New hepatitis B virus of cranes that has an unexpected broad host range. J Virol 77, 19641976.

Prufer, K., Racimo, F., Patterson, N., Jay, F., Sankararaman, S., Sawyer, S., Heinze, A., Renaud, G., Sudmant, P.H., de, F.C., Li, H., Mallick, S., Dannemann, M., Fu, Q., Kircher, M., Kuhlwilm, M., Lachmann, M., Meyer, M., Ongyerth, M., Siebauer, M., Theunert, C., Tandon, A., Moorjani, P., Pickrell, J., Mullikin, J.C., Vohr, S.H., Green, R.E., Hellmann, I., Johnson, P.L., Blanche, H., Cann, H., Kitzman, J.O., Shendure, J., Eichler, E.E., Lein, E.S., Bakken, T.E., Golovanova, L.V., Doronichev, V.B., Shunkov, M.V., Derevianko, A.P., Viola, B., Slatkin, M., Reich, D., Kelso, J., Paabo, S., 2014. The complete genome sequence of a Neanderthal from the Altai Mountains. Nature 505, 43-49. 
Pult, I., Netter, H.J., Bruns, M., Prassolov, A., Sirma, H., Hohenberg, H., Chang, S.F., Frolich, K., Krone, O., Kaleta, E.F., Will, H., 2001. Identification and analysis of a new hepadnavirus in white storks. Virology 289, 114-128.

Rajoriya, N., Combet, C., Zoulim, F., Janssen, H.L.A., 2017. How viral genetic variants and genotypes influence disease and treatment outcome of chronic hepatitis B. Time for an individualised approach? J Hepatol 67, 1281-1297.

Raney, A.K., Milich, D.R., McLachlan, A., 1991. Complex regulation of transcription from the hepatitis $B$ virus major surface antigen promoter in human hepatoma cell lines. J Virol 65, 4805-4811. Rasche, A., Lehmann, F., Konig, A., Goldmann, N., Corman, V.M., Moreira-Soto, A., Geipel, A., van, R.D., Vakulenko, Y.A., Sander, A.L., Niekamp, H., Kepper, R., Schlegel, M., Akoua-Koffi, C., Souza, B.F.C.D., Sahr, F., Olayemi, A., Schulze, V., Petraityte-Burneikiene, R., Kazaks, A., Lowjaga, K.A.A.T., Geyer, J., Kuiken, T., Drosten, C., Lukashev, A.N., Fichet-Calvet, E., Ulrich, R.G., Glebe, D., Drexler, J.F., 2019. Highly diversified shrew hepatitis $B$ viruses corroborate ancient origins and divergent infection patterns of mammalian hepadnaviruses. Proc Natl Acad Sci U S A 116, 17007-17012.

Robertson, B.H., Margolis, H.S., 2002. Primate hepatitis B viruses - genetic diversity, geography and evolution. Rev. Med Virol 12, 133-141.

Rogers, A.R., Harris, N.S., Achenbach, A.A., 2020. Neanderthal-Denisovan ancestors interbred with a distantly related hominin. Science Advances 6.

Roggendorf, M., Kosinska, A.D., Liu, J., Lu, M., 2015. The Woodchuck, a Nonprimate Model for Immunopathogenesis and Therapeutic Immunomodulation in Chronic Hepatitis B Virus Infection. Cold Spring Harb. Perspect. Med 5.

Sa-nguanmoo, P., Thongmee, C., Ratanakorn, P., Pattanarangsan, R., Boonyarittichaikij, R., Chodapisitkul, S., Theamboonlers, A., Tangkijvanich, P., Poovorawan, Y., 2008. Prevalence, whole genome characterization and phylogenetic analysis of hepatitis $B$ virus in captive orangutan and gibbon. J Med Primatol 37, 277-289.

Sall, A.A., Starkman, S., Reynes, J.M., Lay, S., Nhim, T., Hunt, M., Marx, N., Simmonds, P., 2005. Frequent infection of Hylobates pileatus (pileated gibbon) with species-associated variants of hepatitis B virus in Cambodia. J Gen Virol 86, 333-337.

Schaefer, S., 2007. Hepatitis B virus taxonomy and hepatitis B virus genotypes. World J Gastroenterol $13,14-21$.

Schultz, U., Grgacic, E., Nassal, M., 2004. Duck hepatitis B virus: an invaluable model system for HBV infection. Adv. Virus Res 63, 1-70.

Schulze, A., Gripon, P., Urban, S., 2007. Hepatitis B virus infection initiates with a large surface protein-dependent binding to heparan sulfate proteoglycans. Hepatology 46, 1759-1768.

Seeger, C., Mason, W.S., 2000. Hepatitis B virus biology. Microbiol. Mol. Biol. Rev 64, 51-68.

Seitz, S., Habjanic, J., Schutz, A.K., Bartenschlager, R., 2020. The Hepatitis B Virus Envelope Proteins: Molecular Gymnastics Throughout the Viral Life Cycle. Annu Rev Virol.

Seitz, S., lancu, C., Volz, T., Mier, W., Dandri, M., Urban, S., Bartenschlager, R., 2016. A Slow Maturation Process Renders Hepatitis B Virus Infectious. Cell Host. Microbe 20, 25-35.

Seitz, S., Urban, S., Antoni, C., Bottcher, B., 2007. Cryo-electron microscopy of hepatitis B virions reveals variability in envelope capsid interactions. EMBO J 26, 4160-4167.

Shi, W., Carr, M.J., Dunford, L., Zhu, C., Hall, W.W., Higgins, D.G., 2012. Identification of novel intergenotypic recombinants of human hepatitis $B$ viruses by large-scale phylogenetic analysis. Virology 427, 51-59.

Simmonds, P., Midgley, S., 2005. Recombination in the genesis and evolution of hepatitis B virus genotypes. J Virol 79, 15467-15476.

Slagle, B.L., Bouchard, M.J., 2018. Role of HBx in hepatitis B virus persistence and its therapeutic implications. Curr. Opin. Virol 30, 32-38.

Springer, M.S., Meredith, R.W., Gatesy, J., Emerling, C.A., Park, J., Rabosky, D.L., Stadler, T., Steiner, C., Ryder, O.A., Janecka, J.E., Fisher, C.A., Murphy, W.J., 2012. Macroevolutionary dynamics and historical biogeography of primate diversification inferred from a species supermatrix. PLoS. One 7 , e49521. 
Spyrou, M.A., Bos, K.I., Herbig, A., Krause, J., 2019. Ancient pathogen genomics as an emerging tool for infectious disease research. Nat. Rev. Genet 20, 323-340.

Starkman, S.E., MacDonald, D.M., Lewis, J.C., Holmes, E.C., Simmonds, P., 2003. Geographic and species association of hepatitis B virus genotypes in non-human primates. Virology 314, 381-393. Stevens, N.J., Seiffert, E.R., O'Connor, P.M., Roberts, E.M., Schmitz, M.D., Krause, C., Gorscak, E., Ngasala, S., Hieronymus, T.L., Temu, J., 2013. Palaeontological evidence for an Oligocene divergence between Old World monkeys and apes. Nature 497, 611-614.

Stoneking, M., Krause, J., 2011. Learning about human population history from ancient and modern genomes. Nat. Rev. Genet 12, 603-614.

Stramer, S.L., Wend, U., Candotti, D., Foster, G.A., Hollinger, F.B., Dodd, R.Y., Allain, J.P., Gerlich, W., 2011. Nucleic acid testing to detect HBV infection in blood donors. N Engl J Med 364, 236-247.

Suffner, S., Gerstenberg, N., Patra, M., Ruibal, P., Orabi, A., Schindler, M., Bruss, V., 2018. Domains of the Hepatitis B Virus Small Surface Protein S Mediating Oligomerization. J Virol 92.

Suh, A., Brosius, J., Schmitz, J., Kriegs, J.O., 2013. The genome of a Mesozoic paleovirus reveals the evolution of hepatitis B viruses. Nat. Commun 4, 1791.

Suh, A., Weber, C.C., Kehlmaier, C., Braun, E.L., Green, R.E., Fritz, U., Ray, D.A., Ellegren, H., 2014. Early mesozoic coexistence of amniotes and hepadnaviridae. PLoS. Genet 10, e1004559.

Summers, J., Smolec, J.M., Snyder, R., 1978. A virus similar to human hepatitis B virus associated with hepatitis and hepatoma in woodchucks. Proc Natl Acad Sci U S A 75, 4533-4537.

Sureau, C., Salisse, J., 2013. A conformational heparan sulfate binding site essential to infectivity overlaps with the conserved hepatitis B virus a-determinant. Hepatology 57, 985-994.

Szmuness, W., Stevens, C.E., Harley, E.J., Zang, E.A., Oleszko, W.R., William, D.C., Sadovsky, R., Morrison, J.M., Kellner, A., 1980. Hepatitis B vaccine: demonstration of efficacy in a controlled clinical trial in a high-risk population in the United States. N Engl J Med 303, 833-841.

Tacke, F., Amini-Bavil-Olyaee, S., Heim, A., Luedde, T., Manns, M.P., Trautwein, C., 2007. Acute hepatitis $B$ virus infection by genotype $F$ despite successful vaccination in an immune-competent German patient. J Clin Virol 38, 353-357.

Takahashi, K., Brotman, B., Usuda, S., Mishiro, S., Prince, A.M., 2000. Full-genome sequence analyses of hepatitis $B$ virus (HBV) strains recovered from chimpanzees infected in the wild: implications for an origin of HBV. Virology 267, 58-64.

Tatematsu, K., Tanaka, Y., Kurbanov, F., Sugauchi, F., Mano, S., Maeshiro, T., Nakayoshi, T., Wakuta, M., Miyakawa, Y., Mizokami, M., 2009. A genetic variant of hepatitis B virus divergent from known human and ape genotypes isolated from a Japanese patient and provisionally assigned to new genotype J. J Virol 83, 10538-10547.

Tedder, R.S., Bissett, S.L., Myers, R., Ijaz, S., 2013. The 'Red Queen' dilemma--running to stay in the same place: reflections on the evolutionary vector of HBV in humans. Antivir. Ther 18, 489-496.

Testut, P., Renard, C.A., Terradillos, O., Vitvitski-Trepo, L., Tekaia, F., Degott, C., Blake, J., Boyer, B., Buendia, M.A., 1996. A new hepadnavirus endemic in arctic ground squirrels in Alaska. J Virol 70, 4210-4219.

Thomas, D.L., 2019. Global Elimination of Chronic Hepatitis. N. Engl. J Med 380, 2041-2050.

Thomssen, R., Gerlich, W., Bottcher, U., Stibbe, W., Legler, K., Weinmann, E., Klinge, O., Pfeifer, U., 1982. [Preparation and testing of a hepatitis B vaccine (author's transl)]. Dtsch Med Wochenschr 107, 125-131.

Tong, S., Revill, P., 2016. Overview of hepatitis B viral replication and genetic variability. J Hepatol 64, S4-S16.

Torresi, J., 2002. The virological and clinical significance of mutations in the overlapping envelope and polymerase genes of hepatitis B virus. J Clin Virol 25, 97-106.

Tu, T., Urban, S., 2018. Virus entry and its inhibition to prevent and treat hepatitis B and hepatitis D virus infections. Curr Opin Virol 30, 68-79.

van Hemert, F.J., van de Klundert, M.A., Lukashov, V.V., Kootstra, N.A., Berkhout, B., Zaaijer, H.L., 2011. Protein $X$ of hepatitis $B$ virus: origin and structure similarity with the central domain of DNA glycosylase. PLoS. One 6, e23392. 
Velkov, S., Ott, J.J., Protzer, U., Michler, T., 2018. The Global Hepatitis B Virus Genotype Distribution Approximated from Available Genotyping Data. Genes (Basel) 9.

Verschoor, E.J., Warren, K.S., Langenhuijzen, S., Heriyanto, Swan, R.A., Heeney, J.L., 2001. Analysis of two genomic variants of orang-utan hepadnavirus and their relationship to other primate hepatitis Blike viruses. J Gen Virol 82, 893-897.

Wang, B., Yang, X.L., Li, W., Zhu, Y., Ge, X.Y., Zhang, L.B., Zhang, Y.Z., Bock, C.T., Shi, Z.L., 2017.

Detection and genome characterization of four novel bat hepadnaviruses and a hepevirus in China.

Virol J 14, 40.

Wang, Q., Qin, Y., Zhang, J., Jia, L., Fu, S., Wang, Y., Li, J., Tong, S., 2020. Tracing the evolutionary history of hepadnaviruses in terms of e antigen and middle envelope protein expression or processing. Virus Res 276, 197825.

Warner, N., Locarnini, S., 2008. The antiviral drug selected hepatitis B virus rtA181T/sW172* mutant has a dominant negative secretion defect and alters the typical profile of viral rebound. Hepatology 48, 88-98.

Warren, K.S., Heeney, J.L., Swan, R.A., Heriyanto, Verschoor, E.J., 1999. A new group of hepadnaviruses naturally infecting orangutans (Pongo pygmaeus). J Virol 73, 7860-7865.

Watashi, K., Urban, S., Li, W., Wakita, T., 2014. NTCP and beyond: opening the door to unveil hepatitis B virus entry. Int. J Mol. Sci 15, 2892-2905.

WHO, 2019. Hepatitis B; WHO fact sheet; updated July 2019;

http://www.who.int/mediacentre/factsheets/fs204/en/.

Wynne, S.A., Crowther, R.A., Leslie, A.G., 1999. The crystal structure of the human hepatitis B virus capsid. Mol. Cell 3, 771-780.

Yan, H., Zhong, G., Xu, G., He, W., Jing, Z., Gao, Z., Huang, Y., Qi, Y., Peng, B., Wang, H., Fu, L., Song, M., Chen, P., Gao, W., Ren, B., Sun, Y., Cai, T., Feng, X., Sui, J., Li, W., 2012. Sodium taurocholate cotransporting polypeptide is a functional receptor for human hepatitis $B$ and $D$ virus. Elife $1, e 00049$. Yang, J., Xi, Q., Deng, R., Wang, J., Hou, J., Wang, X., 2007. Identification of interspecies recombination among hepadnaviruses infecting cross-species hosts. J Med Virol 79, 1741-1750. Yang, L., Wu, J., Hu, T., Qin, S., Deng, B., Liu, J., Zhang, F., He, B., Tu, C., 2018. Genetic diversity of bat orthohepadnaviruses in China and a proposed new nomenclature. Infect. Genet. Evol 63, 135-143. Zoulim, F., Locarnini, S., 2009. Hepatitis B virus resistance to nucleos(t)ide analogues. Gastroenterology 137, 1593-1608 e1591-1592. 


\section{Figures}

\section{Figure 1}

\section{A}
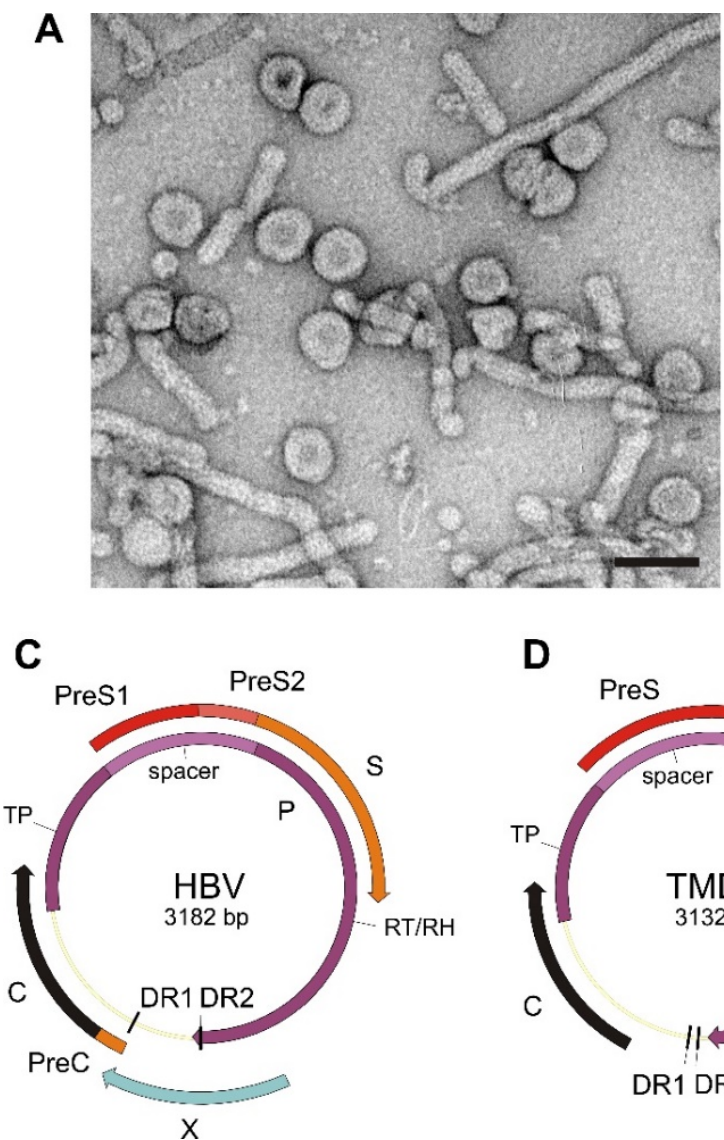

B

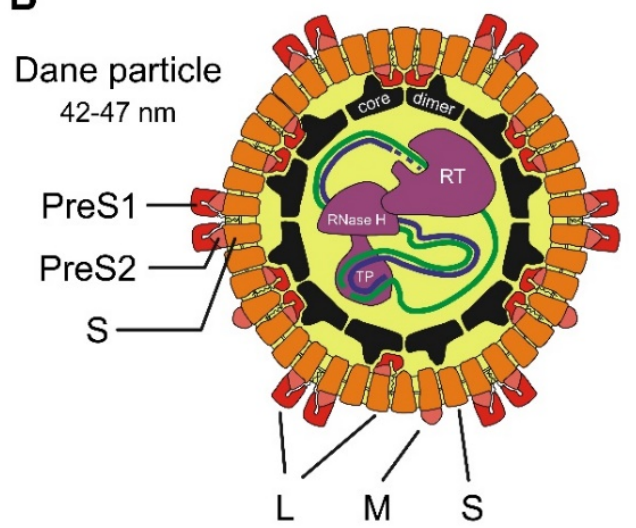

E
D Pres

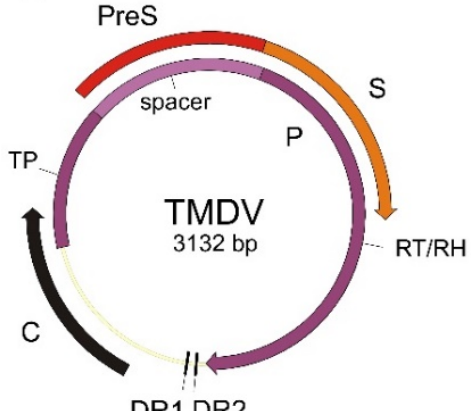

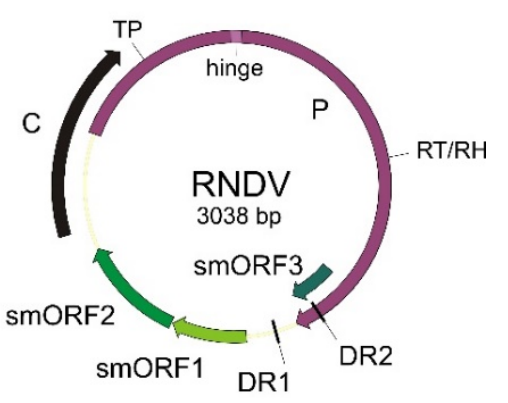

Figure 1. Morphology and genome architecture of hepadnaviruses. A. Transmission electron micrograph of HBV particles purified from cell culture supernatant. Negative stain with uranyl acetate. Spherical 42-nm virions (Dane particles) and filamentous and spherical 20-nm SVP. Scale bar: $50 \mathrm{~nm}$. B. Schematic representation of the Dane particle structure. C-E. Representative genome maps depicting open reading frames. DR1, DR2: direct repeats. C. HBV. D. Tetra metahepadnavirus (TMDV) from the Mexican tetra (Astyanax mexicanus), a blind cavefish. E. Rockfish nackednavirus (RNDV) from the tiger rockfish (Sebastes nigrocinctus). Note the absence of a surface protein gene. smORF: small open reading frames coding for proteins of unknown function. 


\section{Figure 2}

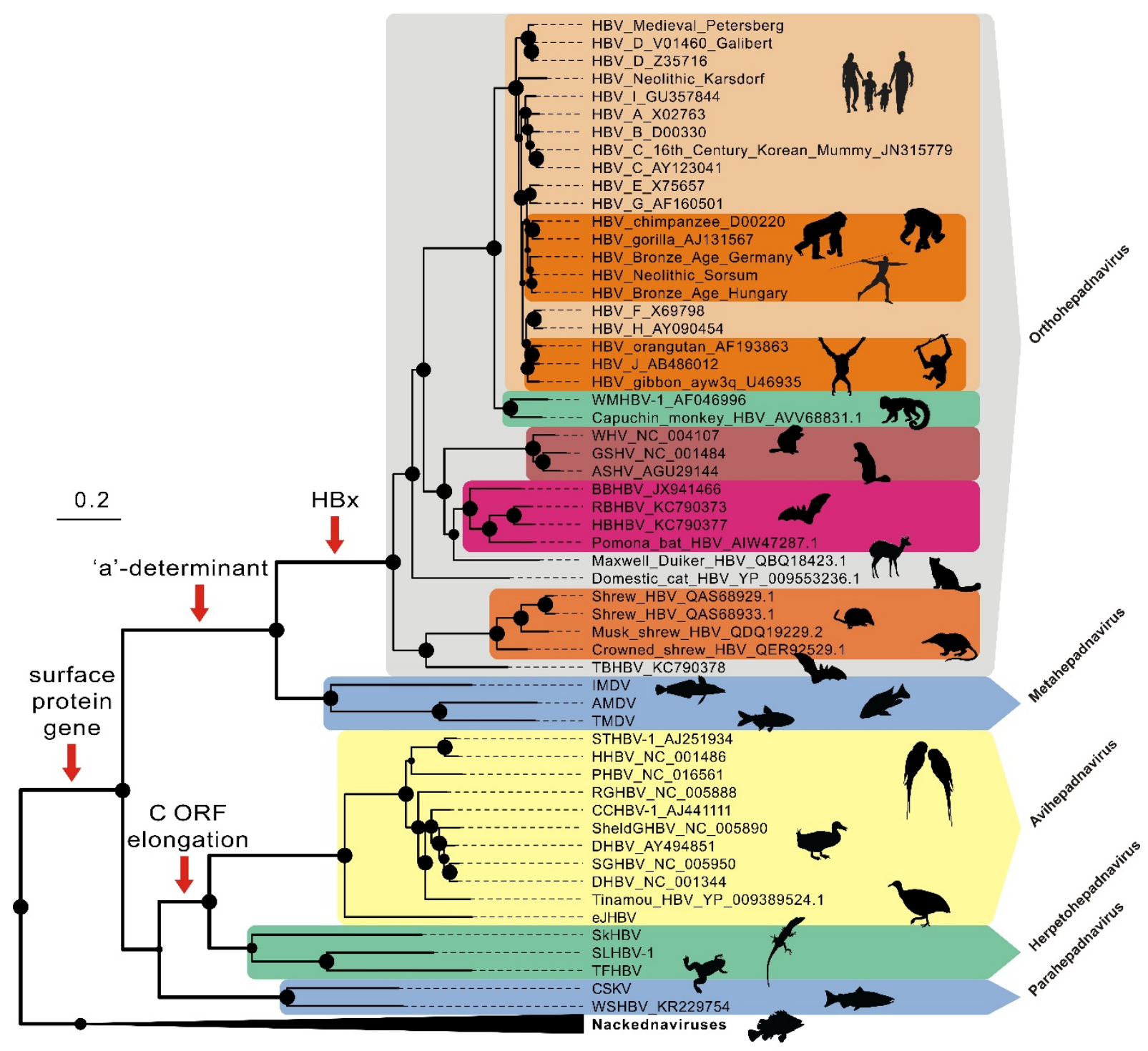

Figure 2. Hepadnavirus phylogeny basing on a multiple sequence alignment of conserved Pol regions and rooted using 13 nackednaviruses as outgroup. The BEAST tool was used to reconstruct this Bayesian tree under the $\mathrm{LG}+\mathrm{G} 4+\mathrm{I}$ substitution model, a relaxed molecular clock with log-normally distributed rates and a Yule speciation prior. Size of the circles at internal branching points is proportional to the posterior probability of a split, which ranges from 0.43 to 1.0 . The unit of the scale bar is average number of substitutions per site. Major evolutionary innovations are marked by red arrows. 


\section{Figure 3}

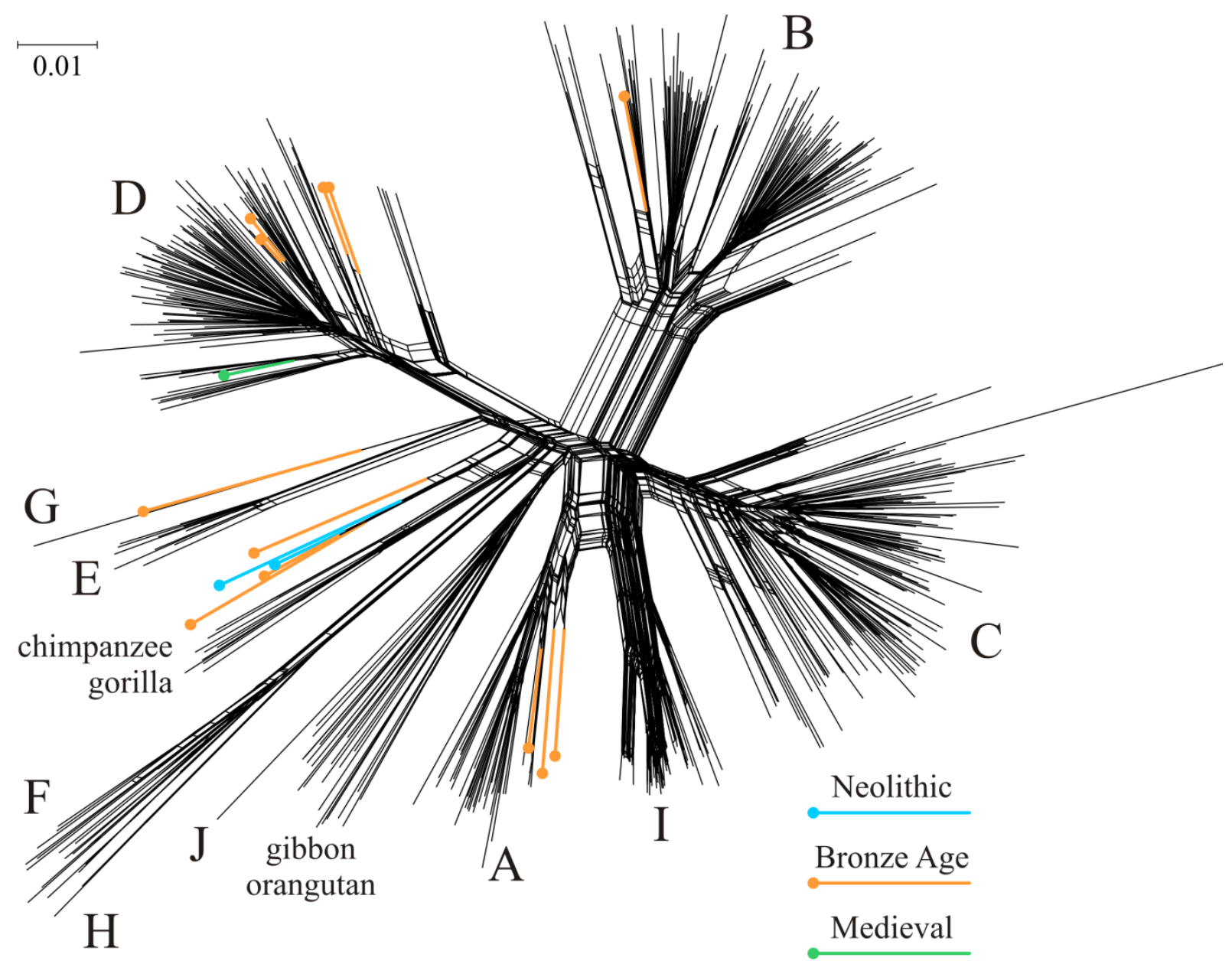

Figure 3. Phylogenetic network of Hepatitis B virus, reconstructed using the SplitsTree tool with default parameters. The network is based on a multiple nucleotide alignment of $552 \mathrm{HBV}$ genome sequences (Krause-Kyora et al., 2018; Muhlemann et al., 2018). HBV genotypes are indicated by capital letters, and the positions of viral lineages infecting non-human apes are marked through host names. Ancient HBV lineages from the Neolithic (blue; 2 isolates), the Bronze Age (orange; 12) and the Medieval period (green; 1) are highlighted by terminal dots. 
Figure 4

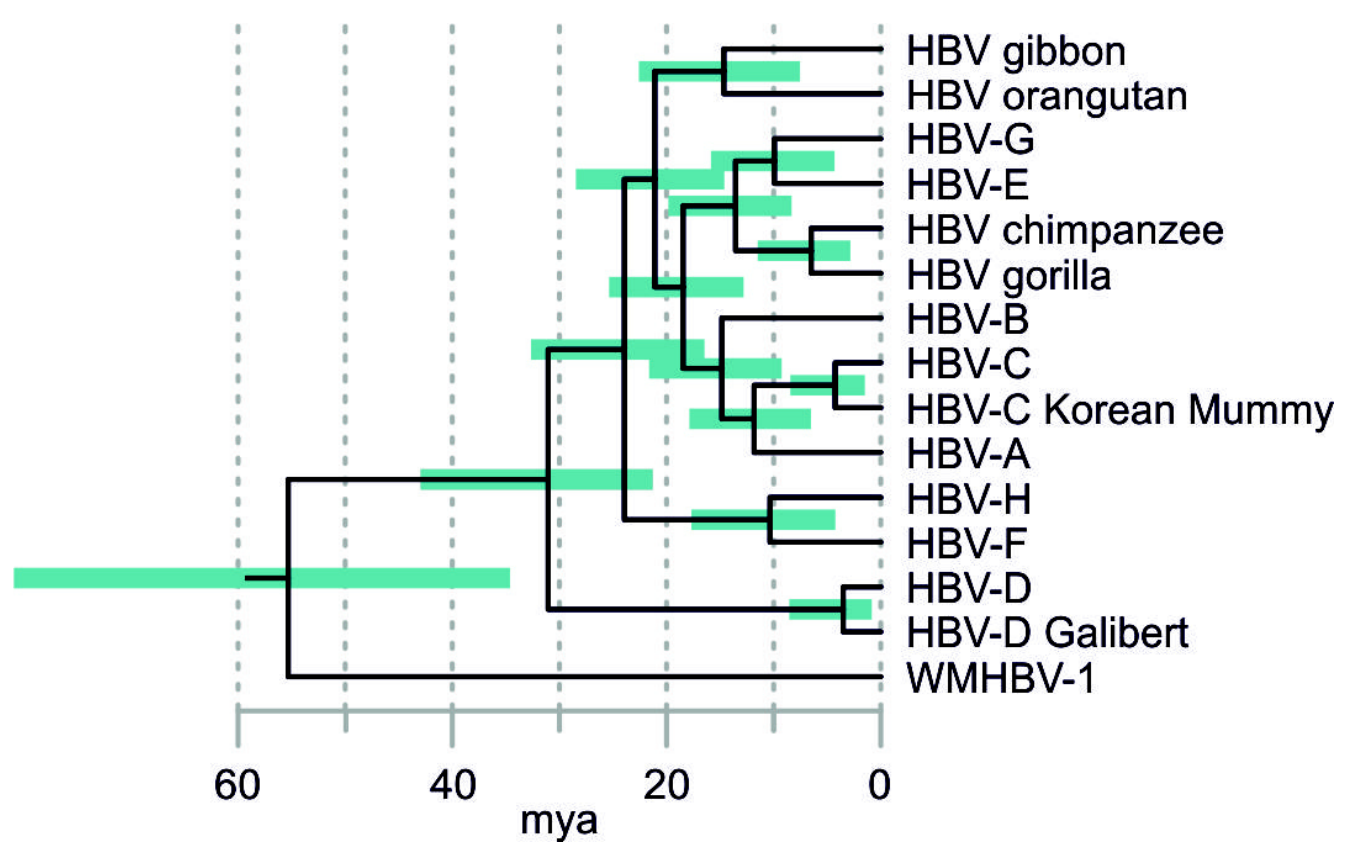

Figure 4. Time-calibrated phylogeny of HBV genotypes. The tree is a subtree of the phylogeny shown in Figure 4 of Lauber et al. (2017). Woolly monkey hepatitis B virus (WMHBV) serves as outgroup. Numbers indicate divergence time estimates in million years ago (mya). Bars represent 95\% confidence intervals. 
Figure 5

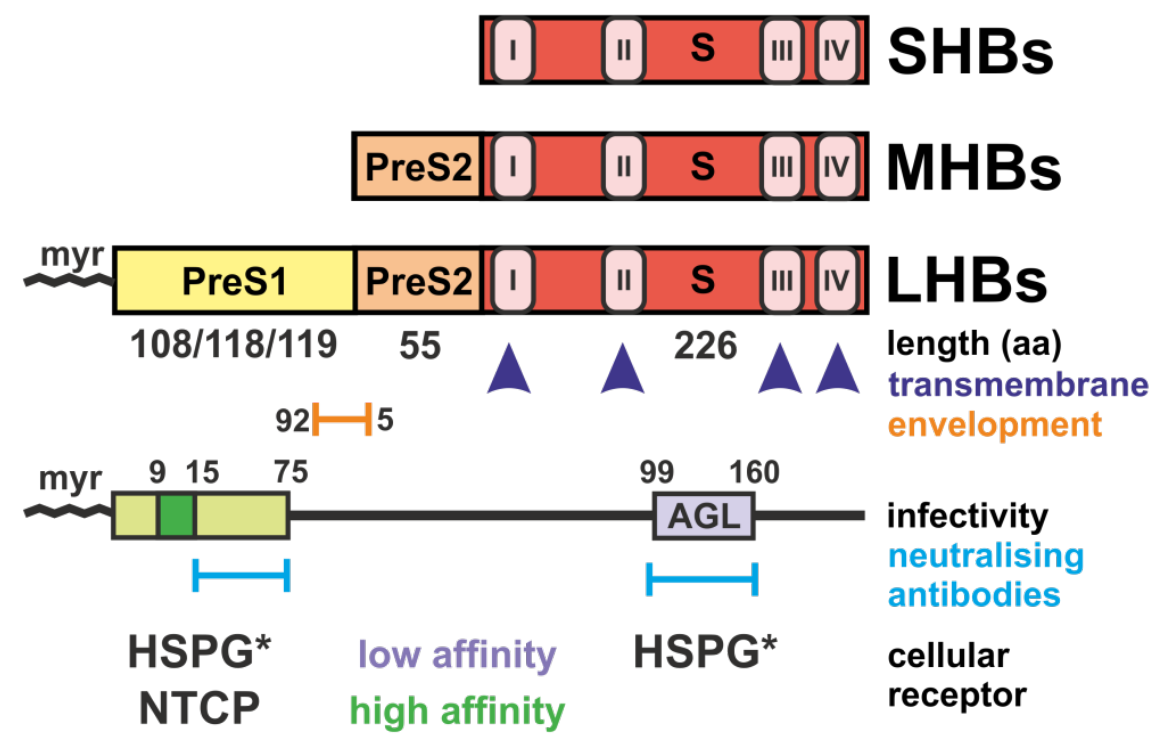

Figure 5. Organization and function of HBV surface proteins. The three hepatitis B virus surface proteins are depicted in their co-carboxy-terminal orientation. The small hepatitis $B$ virus surface protein (SHBs) consists of the $\mathrm{S}$ domain (red), comprising 226 amino acids (aa) and forms at least 4 transmembrane domains (blue arrows). The middle hepatitis B virus surface protein (MHBs) consists of the $\mathrm{S}$ domain and the amino-terminal PreS2 domain (55 aa). Addition of the PreS1 domain (yellow) to the PreS2 and the S domains forms the large hepatitis B virus surface protein (LHBs). The length of the PreS1 domain is 108,118 or 119 aa depending on the HBV genotype. The PreS1 domain is myristoylated at the amino-terminal glycine-2. Envelopment of virions is dependent on a conserved junction of PreS1 and PreS2 within LHBs. HBV infection is initiated by low-affinity binding to cellular heparansulfate proteoglycans (HSPG - *it was reported that this process is mediated by the PreS1 domain (Leistner et al., 2008; Schulze et al., 2007), while another report attributed it to the external antigenic loop (AGL) of the S domain (Sureau and Salisse, 2013)). High-affinity HBV binding leading to infection is mediated by the human liver bile acid transporter NTCP ( $\mathrm{Na}^{+} /$taurocholate cotransporting peptide). A short and highly conserved amino acid stretch (PreS1 aa 9-15, depending on the genotype, dark green) within the amino-terminal 75 aa of myristoylated PreS1 (light green) is essential for infection. The AGL within the $S$ domain and the amino-terminal domain of PreS1 (aa 1575) contain B-cell epitopes that are recognized by neutralizing antibodies. N- and O-glycans of HBV surface proteins were omitted for simplification. 
